ROBINSON, Gwen; McNEILL, Fergus; MARUNA, Shadd. "Castigo en sociedad: La Improbable persistencia de la probation y otras sanciones y medidas comunitarias".

Polít. crim. Vol. 9, № 17 (Julio 2014), Art. 5, pp. 147-181.

[http://www.politicacriminal.cl/Vol_09/n_17/Vol9N17A5.pdf]

\title{
Castigo en sociedad: La improbable persistencia de la probation y otras sanciones y medidas comunitarias. ${ }^{\alpha}$
}

\section{Dr. Gwen Robinson}

Instructor en Justicia Criminal en la Universidad de Sheffield, Inglaterra. g.j.robinson@sheffield.ac.uk

\section{Fergus McNeill}

Profesor de Criminología y Trabajo Social en la Universidad de Glasgow, Escocia. Investigador Asociado en el Scottish Centre For Crime and Justice Research. fergus.mcneill@glasgow.ac.uk

\section{Dr. Shadd Maruna}

Director del Instituto de Criminología y Justicia Criminal y profesor de Justice Studies de la Escuela de Derecho de la Queen's University de Belfast en Irlanda del Norte.

s.maruna@qub.ac.uk

\section{Resumen}

El presente artículo tiene por objeto explorar y explicar las "adaptaciones" clave por las cuales las sanciones en comunidad han buscado legitimación en vista del declive del Estado de Bienestar Penal y del ideal de rehabilitación. Este muestra cómo las sanciones en comunidad han sobrevivido, e incluso prosperado, en estas cambiantes corrientes penales, sociales, y culturales, a pesar de existir muchas predicciones sobre su desaparición. Las cuatro adaptaciones que identificamos y discutimos incluyen los aspectos, respectivamente: managerial; punitivos; de rehabilitación; y reparativos. Concluimos tratando de contribuir nuestro análisis sobre las futuras posibilidades para las sanciones en comunidad y su legitimación.*

Palabras clave: Probation, sanciones en comunidad, rehabilitación, desistimiento.

\section{Abstract}

This paper aims to explore and explain the key "adaptations" by which community sanctions have sought legitimacy in the wake of the decline of penal welfarism and of the

\footnotetext{
${ }^{\alpha}$ Texto publicado, traducido y reproducido con el permiso de "SAGE Publications, London, Los Angeles, New Delhi and Singapore", del original ROBINSON, Gwen, McNEILL, Fergus y MARUNA, Shadd, "Punishment in society: The improbable persistence of probation and other community sanctions and measures" en: SIMON, Jonathan y SPARKS, Richard (eds.), Handbook of Punishment and Society, Londres: Sage, 2013, pp. 321-340. Traducción realizada por Javier Velásquez Valenzuela, abogado, ayudante del depto. de derecho penal de la Universidad Alberto Hurtado, corregida por Mariela Beatriz Vega Nunez traductora y Claudio Vega Ozuljevich.

* N. del T.: Se hace presente que el texto original carecía de abstract, por lo cual se creó uno para estos efectos con la aprobación de los autores.
} 
ROBINSON, Gwen; McNEILL, Fergus; MARUNA, Shadd. "Castigo en sociedad: La Improbable persistencia de la probation y otras sanciones y medidas comunitarias".

rehabilitative ideal. It shows how community sanctions have survived and even thrived in these shifting social, cultural and penal currents despite various predictions of their demise. The four adaptations that we identify and discuss include, respectively, managerial, punitive, rehabilitative, and reparative aspects. We conclude trying to contribute our analysis of the future prospects for community sanctions and their legitimation.

Key words: Probation, community sanctions, rehabilitation, desistance.

\section{Introducción.}

Hacia fines del siglo XX el panorama para la probation* ${ }^{*}$ era bastante sombrío. Pese a haber existido por alrededor de 100 años, durante la década de los años 90 la probation en el Reino Unido, por ejemplo, se decía que era "incomoda, amenazada, insegura de su rol, y para nada confiada de su credibilidad social o política" . Percepciones similares llevaron a la realización de una serie de conferencias e investigaciones de alto perfil sobre el estado de la probation en Estados Unidos a fines de los 90. Por ejemplo, según uno de los expertos que participó en la influyente reunión "Repensando la Probation": "El respeto público que se tiene por la probation es peligrosamente bajo (...) tenemos que darnos cuenta que no contamos con una amplia legitimidad pública". 2 Tan sólo dos años después un informe igualmente prestigioso, titulado "Reinventando la Probation", elevó el nivel de alerta aun más. ${ }^{3}$ Sus autores argumentaban que las sanciones comunitarias estaban sufriendo una "crisis de legitimidad", argumentando que:

\footnotetext{
${ }^{*}$ N. del T.: En la presente traducción, y de manera similar a lo que se ha hecho en otros textos recientes, (Como los recientes trabajos de Diego Zysman Quirós o la traducción de Máximo Sozzo de la "Cultura del Control" de David Garland) se ha optado por mantener sin traducir algunos términos cuya traducción literal no existe, como es el caso de la institución de la "Probation", o bien, su traducción resultaría inexacta en ciertos contextos, como ocurre con el término "Management". Respecto de esta última palabra se ha optado por la práctica extranjerista de Zysman.

${ }^{*}$ N. del T.: Si bien es posible decir que la institución de la "probation" es análoga a la libertad condicional, esto es cierto sólo para en el Reino Unido, dado que para Canadá y algunas partes de Estados Unidos también se utiliza el vocablo para hablar de un equivalente de la libertad vigilada. Es por este motivo que no es posible entregar una definición exacta. Si se desea indagar más sobre los orígenes, desarrollo y practica actual de la probation en el Reino Unido se recomienda ver GELSTHORPE, Loraine y MORGAN, Rod, (eds.), "Handbook of Probation", Cullompton: Willian, 2007, 626 pp. También CANTON, Rob, Probation, Abingdon (Inglaterra): Routledge, 2011, 263 pp. Sobre el caso estadounidense ver PETERSILIA, "Probation in the United States", Crime and Justice, vol. 22 (1997), pp. 149-200, y más recientemente PETERSILIA, Joan, "Community Corrections: Probation, Parole and Prisoner Reentry", en: WILSON, James Q. y PETERSILIA, Joan (Eds.), Crime and Public Policy, New York, NY: Oxford University Press, 2011, pp. 499-531.

${ }^{1}$ GARLAND, David, "Probation and the reconfiguration of crime control", en: BURNETT, Ros (Ed.), The Probation Service: Responding to Change (Proceedings of the Probation Studies Unit First Colloquium), Oxford: University of Oxford Centre for Criminological Research, 1997, p. 3.

2 DICKEY, Walter J. y SMITH, Michael E., "Dangerous Opportunity: Five futures for community corrections: The report from the focus group", Washington D.C.: U.S. Department of Justice, Office of Justice Programs, 1998, p.6. Puede accederse vía electrónica en: http://www.ojp.usdoj.gov/probation/ [Visitado 21.08.2013].

3 BETO, Dan R., CORBETT, Ronald P. y DILULIO, John J., "Getting serious about probation and the crime problem", Corrections Management Quarterly, no 4 (2000), pp. 1-8.
} 
Polít. crim. Vol. 9, № 17 (Julio 2014), Art. 5, pp. 147-181.

[http://www.politicacriminal.cl/Vol_09/n_17/Vol9N17A5.pdf]

“aunque los bajos porcentajes de aprobación [en las encuestas de opinión pública] obviamente se encuentran relacionados con un pobre desempeño, también son señal de un fracaso por parte de la probation de transmitir a la ciudadanía la imagen de un modelo de trabajo que plasme valores ampliamente aceptados y que sirva para una mayor preocupación de la seguridad pública.",4

No obstante, las cosas realmente tocaron fondo el año siguiente. En un artículo titulado ¿El fin de la probation?" publicado en la revista de la Asociación Americana de Probation y Parole, los expertos en corrección comunitaria Maloney, Bazamore y Hudson, sostenían que el modelo norteamericano de la probation había "seguido el camino del Edsel"* en términos de desempeño y reputación. Ellos argumentaban que, tal y como ocurrió con el infame fracaso del automóvil de la compañía Ford, la probation, como marca, debía ser retirada. ${ }^{6}$ Al decir esto, ellos no sólo abogaban por el fin de la práctica tradicional de la probation en Estados Unidos (la que ellos consideraban que se encontraba fundada en la extraña suposición de que la vigilancia y algo de orientación podrían mantener al infractor por el buen camino), sino que también por prescindir del nombre de la "marca" probation.

Entonces ¿Qué ocurrió después? ¿Qué ocurrió con aquella sanción penal, supuestamente en peligro de extinción, a la que solíamos denominar probation? De hecho, los rumores acerca de la inminente extinción de la probation resultaron ser bastante exagerados. No sólo la probation aún está viva, sino que puede que esté más fuerte que nunca. Internacionalmente, las sanciones en la comunidad han crecido rápidamente en número y en importancia desde su concepción ,y en la mayoría de los sistemas penales superan con creces a las sanciones privativas de libertad. En Estados Unidos, a fines del año 2007, la cantidad de personas sujetas a probation o parole, superaba en más de la mitad (más de cinco millones de personas en total) a la cantidad de individuos sujetos a penas privativas de libertad (alrededor de dos millones). ${ }^{8}$ Las instituciones Europeas equivalentes resultan difíciles de determinar dado el amplio rango de definiciones y formas que adoptan las sanciones en la comunidad y las diferencias en los registros oficiales sobre su uso, pero la extensa y

\footnotetext{
${ }^{4}$ BETO/CORBETT/DILULIO, "Getting serious", cit. nota no 3, pp. 1 y 4.

5 MALONEY, Dennis, BAZEMORE, Gordon y HUDSON, Joe, "The end of probation and the beginning of community justice", Perspectives, vol. 25, nº 3 (2001), pp. 24-30.

* N. del T.: El "Edsel" fue un modelo de automóvil fabricado por la compañía de automóviles Ford durante los años 1958-1960, el cual fue un completo fracaso. La expresión "seguir el camino del Edsel" se refiere a algo que ha fracasado y está por desaparecer.

${ }^{6}$ MALONEY/BAZEMORE/HUDSON, “The end”, cit. nota no 5, p. 24.

${ }^{7}$ Estas recientes tribulaciones de la probation pueden haberse vivido más dramáticamente en las jurisdicciones anglosajonas alrededor del mundo, pero en todas partes, por ejemplo en diversos países de la Europa continental, el servicio de la probation parecía enfrentar sus propias dificultades para asegurar o mantener la credibilidad y legitimidad al interior de los sistemas de justicia penales y discurso político criminales. Para un análisis de un caso continental, particularmente interesante, ver la reconfiguración del sistema de trabajo social del sistema penal belga, después del caso "Dutrox". BAUWENS, Aline, "The transformation of offender rehabilitation", tesis doctoral, Bruselas: Vrije Universiteit, 2011.

${ }^{8}$ GLAZE, Lauren E. y BONCZAR, Thomas P., "Bureau of Justice Statistics, Probation and Parole in the United States. NCJ228230”, Washington D.C.: Departamento de Justicia de Estados Unidos (2009). Puede accederse vía electrónica en: http://www.bjs.gov/index.cfm?ty=pbdetail\&iid=1764 [Visitado 21.08.2013].
} 
ROBINSON, Gwen; McNEILL, Fergus; MARUNA, Shadd. "Castigo en sociedad: La Improbable persistencia de la probation y otras sanciones y medidas comunitarias".

reciente investigación de Von Kalmthouth y Durnescu ${ }^{9}$ sugieren una considerable expansión en el uso de dichas sanciones en casi todas las jurisdicciones europeas. Durnescu estima que alrededor de dos millones de personas estaban encarceladas en Europa al momento de su investigación y que, alrededor de tres millones y medio estaban sujetos a alguna forma de sanción en la comunidad. ${ }^{10}$ El hecho de que casi todos los condenados a penas privativas de libertad son (eventualmente) puestos en libertad, a menudo bajo alguna forma de supervisión, significa por supuesto que muchas de estas sentencias involucran algún grado de supervisión en la comunidad, y no lo contrario. Por lo tanto, la gran mayoría del trabajo 'ordinario' (aunque apenas visible) de las sanciones bajo supervisión se realizan a diario en las oficinas de los oficiales de probation o de libertad condicional [parolee], como también en los hogares de los supervisados, y no en instituciones privativas de libertad. $^{11}$

Este artículo tiene por objeto explorar y explicar el enigma detrás de la longevidad y la expansión de las sanciones en la comunidad pese a los diversos diagnósticos sobre la pérdida de su legitimación y de las predicciones sobre su desaparición. Específicamente, abordamos la pregunta: ¿Cómo es que este tipo de sanciones se han adaptado y sobrevivido en las sociedades de la modernidad tardía? Para dicho fin, comenzamos realizando un breve resumen de algunos de los más influyentes e importantes hitos en la historia de las sanciones en la comunidad, antes de elaborar las que creemos son las 'adaptaciones' clave que han caracterizado a las sanciones en la comunidad en su búsqueda por legitimarse en los sistemas penales de las sociedades de la modernidad tardía. Como nuestro análisis revelará, concordamos ampliamente con las observaciones de Hutchinson, ${ }^{12}$ y otros autores, en relación a que el desarrollo del campo penal ha sido caracterizado por un entrelazamiento entre "viejas" y "nuevas" formas y funciones: lo viejo tiende a sobrevivir (o adaptarse) junto a lo nuevo, en vez de ser reemplazado por éste. Nuestro análisis busca establecer lo que vemos como características claves, o facetas, de las sanciones en comunidad contemporáneas que se encuentran más o menos visibles a lo largo de las diversas jurisdicciones (no obstante encontradas en diferentes grados y en diversas combinaciones). Así nosotros no buscamos describir la 'realidad' empírica en un determinado tiempo y lugar, sino destacar algunos de los aspectos claves contra las que las sentencias en comunidad deben analizarse, compararse, y contrastarse a lo largo del tiempo y el espacio. Las características de las sanciones en la comunidad en las que nos hemos centrado - managerial, ${ }^{*}$ punitivo, rehabilitación y reparación - se encuentran, como

\footnotetext{
${ }^{9}$ VON KALMTHOUTH, Anton M. y DURNESCU, Ioan (Eds.), Probation in Europe, Nijmegen: Wolf Legal Publishers/CEP, 2008, passim.

${ }^{10}$ DURNESCU, Ioan, "An exploration of the purposes and outcomes of probation in European jurisdictions", Probation Journal, vol. 55, no 3 (2008), pp. 273-281.

${ }^{11}$ Nos hemos enfocado en las sanciones bajo supervisión y medidas opuestas a las sanciones pecuniarias, que no imponen ningún tipo de supervisión, tales como las multas o la restitución del daño causado a la víctima. Ver O’MALLEY, Pat, "Monetized Justice: Money and Punishment in Consumer Societies", en SIMON, Jonathan y SPARKS, Richard, (Eds.), The Sage Handbook of Punishment and Society, Londres: Sage, 2013, pp. 375-390.

${ }^{12}$ HUTCHINSON, Steven, "Countering catastrophic criminology Reform, punishment and the modern liberal compromise", Punishment \& Society, vol. 8, n 4 (2006), pp. 443-467.

* N. del T.: La traducción exacta para "Management" es gestión o administración, no obstante, el uso que se le da en este contexto se refiere la introducción un razonamiento económico (costo-eficiencia-resultados) en
} 
Polít. crim. Vol. 9, № 17 (Julio 2014), Art. 5, pp. 147-181.

[http://www.politicacriminal.cl/Vol_09/n_17/Vol9N17A5.pdf]

quedará claro más adelante, superpuestas entre sí en vez de ser categorías descritas que combinan elementos instrumentales y expresivos (o afectivos). En nuestra conclusión, centraremos nuestra atención hacia el futuro de las sanciones en comunidad y a la vez nos preguntamos ¿Cómo estas medidas podrían lograr una mayor legitimidad en caso de ser posible?

\section{Un comentario sobre la selección de las palabras.}

Sin embargo, antes de proceder, necesitamos hacernos cargo de algunas cuestiones referentes a definiciones y delineamientos de la materia. Un destacado académico del área ha descrito acertadamente las sanciones en comunidad como un "pez resbaloso". ${ }^{13}$ Es un sector del campo penal alrededor del cual es difícil dibujar límites claros, el que es descrito y etiquetado de forma diferente según cada jurisdicción, y que se ha caracterizado por la aplicación de prácticas innovadoras/diferenciadoras significativas. Incluso el nombre de esta área específica es un asunto debatido. El término preferido de Raynor (muy AngloGales por cierto), penas en la comunidad [community penalties], sufre (como él mismo lo reconoce) de una falla al no incluir a la gran población de individuos sujetos a algunas formas de supervisión después de haber cumplido todo o parte de su pena privativa de libertad. Términos alternativos, populares entre los norteamericanos, tales como 'medidas correccionales en la comunidad' [community corrections], cubren un espectro mayor pero podría decirse que implica una forma particular de una práctica (correccionalismo), la cual está lejos de tener una aplicación universal, incluso dentro de las jurisdicciones en que el término es utilizado. Dado la gama de opciones problemáticas, hemos optado por una etiqueta mucho más neutral, pero distintivamente europea: Sanciones y Medidas en la Comunidad [community sanctions and measures] (en adelante, "CSM"), definidas por el Consejo de Europa como:

“... Aquellas que mantienen al condenado en la comunidad y suponen algunas restricciones de su libertad a través de la imposición de condiciones y/o obligaciones, y que son implementadas por cuerpos designados por la ley para dicho propósito. El término designa cualquier sanción impuesta por la corte o un juez, y cualquier medida tomada antes o en vez de una decisión de sanción así como también formas de ejecutar una sentencia privativa de libertad fuera de un centro penitenciario."

No obstante, el que hayamos optado por la terminología europea no indica un enfoque restrictivo a la experiencia Europea; En efecto, centramos particularmente nuestra atención

la política criminal. Sobre este punto ver GARLAND, David, La Cultura del Control: Crimen y Orden Social en la Sociedad Contemporánea, Trad. SOZZO, Máximo, Barcelona: Gedisa (2001), pp. 305 y ss. También ZYSMAN, Diego, Castigo y determinación de la pena en Estados Unidos, Madrid: Marcial Pons, 2013, pp. 63 y ss.

13 RAYNOR, Peter, "Community penalties: Probation, "What Works" and offender management", en: MAGUIRE, Mike, MORGAN, Rod y REINER, Robert (Eds.), The Oxford Handbook of Criminology, cuarta edición, Oxford: Oxford University Press, 2007, p. 1061.

${ }^{14}$ COUNCIL OF EUROPE "Committee of Ministers: Recommendation $n^{\circ} \mathrm{R}$ (92) 16 of the Committee of Ministers to member states on the European rules on community sanctions and measures: Adopted by the Committee of Ministers on 19 October 1992 at the 482nd meeting of the Ministers' Deputies", p. 11, en: https://wcd.coe.int/com.instranet.InstraServlet?command=com.instranet.CmdBlobGet\&InstranetImage $=5748$

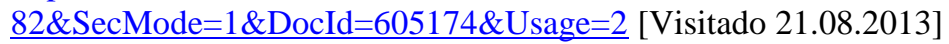


ROBINSON, Gwen; McNEILL, Fergus; MARUNA, Shadd. "Castigo en sociedad: La Improbable persistencia de la probation y otras sanciones y medidas comunitarias".

en los desarrollos que ocurren en el Reino Unido y en Norteamérica, los cuales, se podría decir, han sido las jurisdicciones de mayor influencia internacional en términos de innovación y emulación en algún otro lugar. Nuestra elección por la definición del Consejo de Europea refleja principalmente su inclusividad: tiene éxito en capturar no sólo una amplia variedad de sanciones impuestas por los tribunales, (algunas veces llamadas medidas de "puerta de entrada") las que están entre las sanciones que no implican supervisión (como las multas) y las penas privativas de libertad, sino que también contempla las medidas legales, posteriores a la imposición de una pena privativa de libertad ("puerta trasera"), asociados a esquemas de puesta de libertad temprana (como es la libertad condicional [parole]). En términos generales, lo que las sanciones y medidas comunitarias tienen en común es alguna forma de vigilancia o supervisión de las actividades de los individuos mientras se les mantiene en la comunidad. Lo que la "supervisión" implica, sus fines o propósitos a los que está orientado y quien o quienes asumen la responsabilidad por ella, son todos aspectos que varían tanto internacional como históricamente.

\section{Adaptación y sobrevivencia.}

Existen un número importante de artículos históricos sobre el desarrollo de las sanciones en la comunidad de diversos tipos, la mayoría de los cuales, por necesidad, se concentran en una sola jurisdicción y en un único tipo de sanción. Un buen ejemplo de aquello es la investigación de Vanstone sobre la evolución de la probation en Inglaterra y Gales ${ }^{15}$ (aunque esto involucra comparaciones con la vasta experiencia americana de la probation). Otro documento histórico es el, ahora clásico, estudio de Jonathan Simon sobre el desarrollo de la libertad condicional [parole] al interior de una jurisdicción de los Estados Unidos de Norteamerica (California) ${ }^{16}$. Hay, por supuesto, estudios mucho más amplios, que cubren el surgimiento de la modernidad penal, como es el trabajo Castigo y Estado de Bienestar de David Garland, ${ }^{17}$ que (de forma indirecta) ofrecen contribuciones claves para la literatura histórica de las sanciones en comunidad. Todos estos trabajos localizan los orígenes formales y legales de las sanciones en comunidad en el contexto de los cambios sociales, políticos y culturales que coalicionaron alrededor del comienzo del siglo XX, e inauguraron una penalidad moderna específica que llevó el bienestar o la reforma de los individuos al ámbito de responsabilidad del estado.

Las primeras sanciones en la comunidad esencialmente formalizaron una gama de prácticas que habían estado previamente en el ámbito de lo que Garland llamó como "filantropía penal", entregándoles autoridad legal (por ejemplo, en Inglaterra y Gales a través de la "Probation of Offenders Act 1907"; en California mediante el establecimiento de un sistema de libertad condicional [parole] en 1893), extendiendo su alcance, creando instituciones especializadas y agencias encargadas de "disciplinar" (en un sentido Foucaultiano) o "normalizar" a aquellos sujetos considerados aptos. Entonces, así como Garland ve la sanción penal moderna como la "matrona" del sistema de probation en Inglaterra y Gales, también Simon reconoce los orígenes de la libertad condicional [parole]

\footnotetext{
${ }^{15}$ VANSTONE, Maurice, Supervision offenders in the community, Aldershot: Ashgate, 2004.

${ }^{16}$ SIMON, Jonathan, Poor Discipline: Parole and the social control of the underclass 1890-1990, Londres: University of Chicago Press, 1993.

${ }^{17}$ GARLAND, David, Punishment and Welfare, Aldershot: Gower, 1985.
} 
Polít. crim. Vol. 9, № 17 (Julio 2014), Art. 5, pp. 147-181.

[http://www.politicacriminal.cl/Vol_09/n_17/Vol9N17A5.pdf]

en la tradición moderna y la búsqueda de la "normalización" de los ex-infractores de ley. Esta "normalización", Simon sostiene, progresó de ser un modelo basado en la participación en el mercado del trabajo a ser un modelo "clínico" de "rehabilitación a través de la modificación de la personalidad". De forma similar, las primeras décadas del siglo $\mathrm{XX}$ atestiguaron una transformación en las prácticas de la probation ya que ideas sobre la reformación moral dieron paso a un discurso más científico centrado en el diagnóstico, tratamiento y "rehabilitación", que, aunque profundo, representaron una importante continuación de las narrativas modernistas y de "celo transformador". 18

Con sus orígenes formales firmemente alojados en los cimientos del "modernismo penal", las sanciones en comunidad han estado profundamente implicadas en la "crisis" de éste, ${ }^{19}$ aspectos que no necesitamos detallar nuevamente acá. En este contexto, los debates académicos y de políticas públicas han centrado sus estrategias en la adaptación, y en la búsqueda de modos de ejercer el poder y legitimar las narrativas de las sanciones en comunidad en contextos sociales que han sido variadamente caracterizados como "postindustriales", "post modernos" o "post-disciplinarios", entre otros términos. ${ }^{20}$ El trabajo de Simon sobre el caso particular de California es una contribución clave a este debate, porque identifica un cambio fundamental en las formas de control que se encuentran explícitamente ligadas al colapso del modernismo penal. En el núcleo de su libro Mala disciplina se encuentra el cambio decisivo que observa Simon, desde mediados de los años 70, se da lo que él denomina como el cambio de una libertad condicional "clínica" a una "managerial" - esta última caracterizada significativamente por bajas expectativas y por un funcionamiento (a modo de reminiscencia de "Sociedades de control" de Deleuze) orientado a ser un mecanismo para asegurar los "límites" de las comunidades canalizando a los sujetos menos estables de vuelta a la prisión.

${ }^{18}$ BOTTOMS, Anthony, "An introduction to the coming crisis", en: BOTTOMS, Anthony y PRESTON, Ronald H. (Eds.) The Coming Penal Crisis, Edinburgo: Scottish Academic Press, 1980, pp. 1-24. También GARLAND, Punishment and Welfare, cit. nota $\mathrm{n}^{\circ}$ 17, passim, $y$ GARLAND, David, The Culture of Control. Crime and Social Order in Contemporary Society, Oxford: Oxford University Press, 2001, passim. N. de T.: De este último libro existe una traducción al español GARLAND, David, La Cultura del Control: Crimen y Orden Social en la Sociedad Contemporánea, Trad. SOZZO, Máximo, Barcelona: Gedisa, 2005.

${ }^{19}$ GARLAND, David, Punishment and Modern Society, Oxford: Clarendon, 1990, passim; ver también GARLAND, The Culture of Control, cit. nota $\mathrm{n}^{\mathrm{o}} 18$, passim. N. de T.: También existe una traducción al español. Ver GARLAND, David, Castigo y Sociedad Moderna, Trad. RUIZ DE LA CONCHA, Berta, Ciudad de México: Siglo XXI Editores, 1999.

${ }^{20}$ BELL, Daniel, The coming of post-industrial society, New York: Basic Books, 1973; también LYOTARD, Jean-Francois, The Postmodern condition: A report on Knowledge, Manchester: University Press, 1984, SIMON, Jonathan, “The Ideological effects of actuarial practices”, Law \& Society Review, vol. 22 (1988), pp. 771-800, BAUMAN, Zygmunt, Modernity and Ambivalence, Cambridge: Polity Press, 1991 y DELEUZE, Gilles, "Postscript on the Societies of Control", en: DELEUZE, Gilles, Negotiations: 1972-1990, New York: Columbia University Press,1995. N. de T.: Respecto del texto de Lyotard es posible encontrar una traducción al español: LYOTARD, Jean-François, La condición post-moderna: Un informe sobre el saber, Madrid: Editorial Cátedra, 1987. Sobre el caso de Bauman, cuya obra se ha traducido profusamente al español ver BAUMAN, Zygmunt, Modernidad y Ambivalencia, AGUILUZ, Enrique (trad.), Barcelona: Anthropos Editorial, 1991/2005. El texto de Deluze por su parte puede encontrarse en DELEUZE, Gilles, "Post-Scriptum sobre las sociedades de control", en: DELEUZE Gilles, Conversaciones 1972-1990, PARDO, José Luis (Trad.), Valencia: Pre-Textos, 1995/1999, pp. 277-286. 
ROBINSON, Gwen; McNEILL, Fergus; MARUNA, Shadd. "Castigo en sociedad: La Improbable persistencia de la probation y otras sanciones y medidas comunitarias".

El análisis de Simon sobre la libertad condicional [parole] es parte de una amplia línea de investigaciones que han utilizado el marco teórico de Foucault para analizar las variaciones en el ejercicio del poder, desde los modos de control normalizadores o disciplinarios característicos de la penalidad moderna, hacia un sistema actuarial, una "nueva penología managerial". ${ }^{21}$ En las últimas dos décadas, mucha de la atención de la academia ha estado dirigida a evaluar hasta qué punto la tesis de la "nueva penología" representa una acertada caracterización de la evolución del campo de las sanciones en comunidad, y si el relato de Simon de la "libertad condicional managerial" [managerial parole] es un ejemplo típico o extremo de las sanciones en comunidad contemporáneas. Generalmente, bajo nuestro punto de vista, consideramos que es demasiado simplista identificar cualquier "discurso de reemplazo" de las medidas y sanciones en comunidad. Esto no sólo por las significativas diferencias que se dan en las diversas jurisdicciones, sino que también porque la "realidad" es mucho más compleja.

Las sanciones en la comunidad de la modernidad tardía se han caracterizado por la desaparición de la coherente meta-narrativa o propósito que el estado de bienestar penal alguna vez proveyó (o más específicamente el "ideal de la rehabilitación"); ${ }^{22}$ pero las adaptaciones que han ocurrido en su secuela, han sido múltiples, variadas y fluidas. ${ }^{23}$ Como las siguientes secciones de este artículo permitirán dejar en claro, la adopción de los discursos y practicas manageriales y actuariales no han sido las únicas formas de adaptación y sobrevivencia abiertas a la probation. En efecto, como Stan Cohen predijo hace un cuarto de siglo atrás, ${ }^{24}$ tal vez la más notable característica de las sanciones en comunidad en los últimos 30 ó 40 años han sido la proliferación y diversificación de sus formas y manifestaciones institucionales, de sus tecnologías y prácticas y, por lo menos en algunas partes, de sus cimientos ideológicos. Por tanto, hemos atestiguado no solo una reelaboración discursiva y una re-configuración de la tradicional gama de sanciones y medidas, como son la probation o la libertad condicional [parole], a través de las nuevas narrativas y técnicas, sino que también el surgimiento de nuevas formas de sanciones en comunidad, como son el trabajo a beneficio de la comunidad, la innovaciones en justicia comunitaria o el monitoreo electrónico. Es también importante notar que, ya sean antiguas o nuevas, las mismas sanciones en comunidad han sido "publicitadas" de formas diferentes a nivel internacional.

En las siguientes secciones, identificamos algunas de las principales adaptaciones en el campo de las CSM que han podido ser observadas internacionalmente a lo largo de los últimos treinta años. Hemos agrupado estos patrones en cuatro "visiones" de CSM, que hemos caracterizado como "managerial", "punitivas", "rehabilitadoras" y "reparatorias".

\footnotetext{
${ }^{21}$ Así en SIMON, Jonathan, "The emergence of a risk society: Insurance, law and the State", Socialist Review vol. 95 (1987), pp. 61-89. SIMON, "The Ideological effects", cit. nota n² 20. También ver FEELEY, Malcolm y SIMON, Jonathan, "The New Penology: Notes on the emerging strategy of corrections and its implications", Criminology vol. 30 (1992), pp. 449-474 y FEELEY, Malcolm; SIMON, Jonathan, "Actuarial justice: The emerging new criminal law", en: NELKEN, D. (Ed.), The futures of criminology, Londres: Sage Publications, 1994, pp. 173-201.

${ }^{22}$ SIMON, Poor Discipline, cit. nota $\mathrm{n}^{\circ} 16$.

${ }^{23}$ LYNCH, Mona, "Waste Managers? The New Penology, Crime Fighting, and Parole Agent Identity", Law \& Society Review, Vol. 32, n 4 (1998), pp. 839-870.

${ }^{24}$ COHEN, Stan, Vision of social control, Cambridge: Polity Press, 1985.
} 
Polít. crim. Vol. 9, № 17 (Julio 2014), Art. 5, pp. 147-181.

[http://www.politicacriminal.cl/Vol_09/n_17/Vol9N17A5.pdf]

En la ultima sección de este trabajo abordaremos hasta qué punto estas diversas adaptaciones han permitido a las sanciones en comunidad, y también a las organizaciones y profesionales encargados de su administración, para presentarlas como respuestas coherentes y legitimas al delito en las sociedades de la modernidad tardía.

\section{Sanciones en comunidad Manageriales.}

Si es que existe un punto de consenso en el eternamente disputado campo de la penalidad, quizás sea la idea de que los sistemas penales, conjuntamente con otros servicios públicos como la educación, la salud y otros similares, se han visto crecientemente dominados por estrategias e intereses manageriales. ${ }^{25}$ Nosotros creemos que este tema es una parte clave para la historia de los esfuerzos por reforzar la legitimidad de las sanciones en comunidad en las sociedades de la modernidad tardía, pero de ningún modo se trata de historia completa.

Aunque es difícil resumir los diversos aspectos del manageralismo en la justicia criminal, o también en otros contextos, el núcleo duro de los diversos relatos sobre las consecuencias del manageralismo en el sistema penal se encuentran en la noción de "sistemización": esto es, la transformación de lo que había sido una serie de instituciones u organizaciones relativamente independientes (como los tribunales, la policial, la prisión, los servicios de probation, etc.) en un "sistema". Para Bottoms, este proceso de sistemización ha tenido la tendencia, en la mayoría de las jurisdicciones, ${ }^{26}$ de adoptar características tales como: un énfasis en la cooperación inter-institucionales para poder satisfacer las metas del sistema; declaraciones de misiones individuales, por cada institución o agencia involucrada en el sistema penal que sirven a las metas generales del sistema: y la creación de indicadores clave de desempeño para cada institución o agencia que tiene la tendencia a enfatizar la eficiencia interna de los procesos en vez de la efectividad de estos en relación con el objetivo global. Como Garland ha destacado, ${ }^{27}$ la sistemización ha permitido la adopción grupal de una variedad de recursos para lidiar con el problema del delito en un campo que se ha reconfigurado por la aceptación de que el delito es un "hecho social normal": un riesgo que debe ser administrado o gestionado en vez de un problema social que debe ser eliminado. Los imperativos claves de una penología managerialista son entonces enfocados en objetivos limitados de "administrar una población permanentemente peligrosa mientras se trata de mantener el funcionamiento del sistema a un costo mínimo." 28

No resulta difícil discernir algunas de las formas en que las sanciones en comunidad y las instituciones o agencias responsables por implementar tales sanciones han sido

\footnotetext{
${ }^{25}$ PETERS, Antoine G., "Main currents in criminal law theory", en: DIJK, Jan van, HAFFMANS, C. et al. (Eds.), Criminal Law in Action. Londres: Kluwer law and taxation publishers, 1986, pp. 19-36. También ver, FEELEY/SIMON, "The New Penology", cit. nota n ${ }^{0}$ 21, passim y FEELEY/SIMON, "Actuarial justice”, cit. nota $\mathrm{n}^{\circ} 21$, passim, y BOTTOMS, Anthony, "The philosophy and politics of punishment and sentencing", en: CLARKSON, Chris y MORGAN, Rod (Eds.), The politics of sentencing reform, Oxford: Clarendon Press, 1995, pp. 17-79; GARLAND, David, "The Limits of the Sovereign State: Strategies of Crime Control in Contemporary Society", British Journal of Criminology, vol. 36, nº 4 (1996), pp. 445-471.

${ }^{26}$ BOTTOMS, "The philosophy and politics", cit. nota $\mathrm{n}^{\circ} 25$, passim.

${ }^{27}$ GARLAND, "The Limits", cit. nota $\mathrm{n}^{\circ} 25$, passim.

${ }^{28}$ FEELEY/SIMON, "The New Penology”, cit. nota n 21, p. 463.
} 
ROBINSON, Gwen; McNEILL, Fergus; MARUNA, Shadd. "Castigo en sociedad: La Improbable persistencia de la probation y otras sanciones y medidas comunitarias".

reelaborados a lo largo de dichas ideas matrices, y como estos desarrollos han ayudado a reforzar su legitimidad "sistémica". Por ejemplo, en muchas jurisdicciones las CSM han sido valoradas más por lo que pueden hacer para otras partes del "sistema" que, por lo que ellas pueden hacer por los individuos que se encuentran bajo su supervisión en la comunidad. Se puede decir que el ejemplo clave de esto es la adopción por muchas jurisdicciones, en los años 80 , de una pragmática racional para las sanciones en comunidad que enfatiza la adopción de alterativas para las penas privativas de libertad creíbles. En este punto, la principal motivación para la ampliación de las "acciones de mercado" de las CSM era aliviar la presión sobre, y a expensas, de las prisiones. ${ }^{29}$ Otro importante ejemplo de las funciones sistemáticas de las CSM en reducir los costos de la prisión, dicen relación con la supervisión de aquellos sujetos condenados que habiendo cumplido parte de la pena privativa de libertad, les ha sido otorgada la libertad condicional, población que en varias jurisdicciones se ha incrementado. ${ }^{30}$ El incremento en la tasa de sujetos sometidos a penas privativas de libertad y la duración de las sentencias han fomentado el uso de "válvulas de seguridad", a través de los mecanismos de "libertades anticipadas" [Early releases], los que, en consecuencia, aumentaron el número de individuos bajo una supervisión posterior a la privativa de libertad (sea bajo beneficios [licence] o libertad condicional [parole]). ${ }^{31}$

Estos desarrollos son sustentados por un cambio en el entendimiento de las instituciones y agencias encargadas de las CSM, las que ahora son vistas como aliados en el manejo y gestión de los infractores de ley junto a otras partes del sistema, tales como la policía y los servicios penitenciarios, donde previos conflictos ideológicos habrían hecho dicha colaboración problemática, si es que no inviable. Esto se ha vuelto evidente, por ejemplo, en Inglaterra y Gales, donde se han establecido colaboraciones formales entre la policía y los servicios de la probation para gestionar y administrar varias categorías de individuos de "alto riesgo" en la comunidad. ${ }^{32}$ Tales asociaciones, como la notable operación "Nightlight" en Boston, ${ }^{33}$ son menos inusuales en el contexto Norte Americano, dado que desde hace tiempo las autoridades encargadas de la probation y especialmente autoridades encargadas de individuos bajo libertad condicional [parole], han entendido su rol, parcialmente por lo menos, como uno de resguardo de la ley y orden público. ${ }^{34}$ Además, en muchos estados de Estados Unidos, las autoridades de probation y libertad condicional [parole] son administradas dentro de las mismas agencias que las prisiones. Esta estructura, al estilo de Estados Unidos, de "servicios correccionales" ha surgido recientemente en Inglaterra y Gales con el nacimiento del "Servicio Nacional de Gestión de Infractores de

${ }^{29}$ RAYNOR, Peter, Probation is an alternative to custody, Aldershot: Avebury, 1988, passim. y VASS, Anthony, Alternative to prison, Londres: Sage Publications, 1990, passim.

${ }^{30}$ PADFIELD, Nicola, VAN ZYL SMIT, Dirk y DÜNKEL, Frieder, Release from prison: European policy and practice, Cullompton: Willian, 2010, passim.

${ }^{31}$ CAVADINO, Mick y DIGNAM, James, The Penal system: Introduction, cuarta edición, Londres: Sage Publications, 2007, passim.

32 KEMSHALL, Hazel y MAGUIRE, Mike, "Public protection, partnership and risk penality: the multiagency risk management of sexual and violent offenders", Punishment and society, vol. 3, no 2 (2001), pp. 237-264.

${ }^{33}$ CORBETT, Ronald P., "Reinventing probation and reducing youth violence: Boston's Operation Night Light" en: KARP, David R.; TODD, Clear (Eds.), What is community justice? Case studies of restorative justice and community supervision, Thousand Oaks, CA: Sage Publications, 2002, pp. 111-134, passim.

${ }^{34}$ SIGLER, Robert T. y McGRAW, Bridgett, "Adult Probation and Parole Officers: Influence of Their Weapons, Role Perceptions and Rule Conflict”, Criminal Justice Review, vol. 9 (1984), pp. 28 - 32, passim. 
Polít. crim. Vol. 9, № 17 (Julio 2014), Art. 5, pp. 147-181.

[http://www.politicacriminal.cl/Vol_09/n_17/Vol9N17A5.pdf]

Ley" [National Offender Management Service] (en adelante, "NOMS"), estableciendo un objetivo común tanto para la prisión como para la probation: "la protección de la sociedad". 35

Paralelamente a estos desarrollos también hemos visto evidencia de una redefinición y una reducción de los criterios utilizados para evaluar el desempeño de las instituciones encargadas de las CSM, con mucho más énfasis en los servicios prestados [outputs], que en los resultados [outcomes] que dichos servicios tienen. Por ejemplo, han surgido "Estándares Nacionales" para las CSM en diversas jurisdicciones a lo largo de los últimos 20 años, y la tendencia que ha sido observada en dichos estándares es la de enfatizar la oportunidad de los procesos en vez de su calidad o efectividad. Mientras tanto, algunos de los rasgos de la "justicia actuarial", descrita por Feeley y $\operatorname{Simon}^{36}$ se han vuelto evidentes en el surgimiento y propagación de las nuevas tecnologías actuariales orientadas a la evaluación de los riesgos, así como también de los nuevos tipos de sanciones de monitoreo, orientadas a lo que Feeley y Simon se refieren como "Management en el lugar". Los toques de queda monitoreados electrónicamente y los test de drogas son probablemente los mejores ejemplos de estas tendencias. ${ }^{37}$ El surgimiento de un discurso de "Gestión o administración de delincuentes" en las jurisdicciones del Reino Unido es otro ejemplo del descenso de las expectativas. $^{38}$

Esta idea manageralista de que los objetivos "sistémicos" son fácilmente alcanzables o generan legitimidad sin problema, sin embargo, no ha sido necesariamente confirmada. ${ }^{39}$ Tomando como ejemplo la función de ser una "alternativa a las penas privativas de libertad", esto ciertamente aparece, a la luz de los hechos, ser un objetivo mucho más asequible que la meta de reformar a los individuos o hacer que enderecen sus vidas. No obstante, en la práctica, incluso este objetivo ha sido difícil de alcanzar: el resultado de las investigaciones sobre este tema ha tendido a demostrar que las sanciones en comunidad son raramente usadas como alternativas genuinas a las penas privativas de libertad. Por ejemplo, una investigación realizada en Inglaterra y Gales a fines de los años 70 descubrió que tan sólo la mitad de las personas condenadas a sentencias en servicio de la comunidad eran realmente alejadas de la prisión, aun cuando este objetivo se encontraba explícito al momento de imponer esta sanción; respecto del resto, la imposición de la sanción de servicios a la comunidad parecía ser realmente una alternativa a la imposición de penas de multa o probation. ${ }^{40}$ Tonry y Lynch $^{41}$ sostienen que la evidencia relacionada con los

\footnotetext{
${ }^{35}$ RAYNOR, Peter y VANSTONE, Maurice, “Towards a correctional service” en: GELSTHORPE, Loraine; MORGAN, Rod (Eds.), Handbook of Probation, Cullompton: Willan, 2007, pp. 59-89.

${ }^{36}$ FEELEY/SIMON, "Actuarial justice", cit. nota no 21, passim.

${ }^{37}$ NELLIS, Mike, "Electronic monitoring: Towards integration into offender Management", en: McNEILL, Fergus; RAYNOR, Peter; TROTTER, Chris (Eds.), Offender Supervision: New directions in theory, research and practice, Cullompton: Willan, 2010, pp. 509-533, passim.

${ }^{38}$ ROBINSON, Gwen, "What works in offender management?", Howard Journal of criminal justice, vol. 44, n 3 (2005), pp. 307-318, passim.

39 WODAHL, Eric, OGLE, Robbin y HECK Cary, "Revocation trends: a threat to the legitimacy of community based corrections", The Prison Journal, vol. 91, n 2 (2011), pp. 207-226, passim.

${ }^{40}$ PEASE, Ken, "Community Service Orders", en: TONRY, Michael y MORRIS, Norval (Eds.), Crime and Justice, Chicago: Chicago University Press, 1985, pp. 51-94, passim.

${ }^{41}$ TONRY, Michael y LYNCH, Mary, "Intermediate Sanctions", Crime and Justice, vol. 20 (1996), pp. 99144, passim.
} 
ROBINSON, Gwen; McNEILL, Fergus; MARUNA, Shadd. "Castigo en sociedad: La Improbable persistencia de la probation y otras sanciones y medidas comunitarias".

programas de "sanciones intermedias" que fueron desarrollados en Estados Unidos durante los años 80 y 90 demuestran un fenómeno similar: pocas veces dichos programas alejaron a grandes números de individuos de la prisión. En efecto, cuando se ha incrementado el uso de las CSM, esto casi siempre ha tendido a ser a expensas de un descenso de los tiempos de duración de las sanciones, llevando a lo que Cohen ${ }^{42}$ ha llamado "ampliación de la red" [net-widening] y "adelgazamiento de la red" [mesh thinning]. Es decir, las CSM frecuentemente atraen un mayor número de infractores de baja peligrosidad a la red del sistema penal de lo que podría haber sido el caso de no haberse impuesto este tipo de sanciones, y les imponen sanciones no menos severas. ${ }^{43}$

Un problema relacionado con lo anterior es la llamada "puerta giratoria" de las prisiones. ${ }^{44}$ Pese a las expectativas reduccionistas del sistema penal aludidas anteriormente, en la mayoría de los casos las formas de supervisión post-pena privativa de libertad más intensas, y quizás más adversas al riesgo, han aumentado las tasas de reincidencia y por lo tanto también la población de las prisiones. ${ }^{45}$ En años recientes, hasta a un $40 \%$ de las personas sujetas a libertad condicional [parolees], a lo largo de todo Estados Unidos, esta se les fue revocada [parole] por haber cometido un nuevo delito o bien por haber cometido una violación técnica de las condiciones impuestas al momento de imponerle la libertad condicional [parole] (por ejemplo, dar positivo en un test de drogas, fallar en seguir un tratamiento, no asistir a las entrevistas con su oficial de libertad condicional, etc.). ${ }^{46}$ En efecto, el número de sujetos bajo libertad condicional [parolees] a quienes se les revocó la misma en Estados Unidos sufrió un incrementó de más de un $800 \%$ en menos de tres décadas. ${ }^{47}$ Además, estas cifras totales, ocultan variaciones perturbadoras entre los distintos estados. Por ejemplo, California ha tenido experiencias particularmente notorias con la revocación de las libertades condicionales con un consiguiente re-encarcelamiento. En el año 2006, casi dos tercios de los sujetos que ingresaron a las prisiones administradas por el estado lo hacían por violación de la libertad condicional, y un tercio de ellos reingresaba a la cárcel por violar las condiciones técnicas de esta. ${ }^{48}$

Esta aproximación a la libertad condicional como si fuese una "gestión de desperdicios" ha sido ampliamente criticada, ${ }^{49}$ y en efecto Wodahl, Ogle y Heck ${ }^{50}$ convincentemente

\footnotetext{
${ }^{42}$ COHEN, Vision of social control, cit. nota ${ }^{\circ} 24$, passim.

${ }^{43}$ BOTTOMS, Anthony, REX, Sue y ROBINSON, Gwen, "How did we get here?" en: BOTTOMS, Anthony, REX, Sue; ROBINSON, Gwen (Eds.), Alternatives to prison: Options for an insecure society, Cullompton: Willan, 2004, pp. 1- 27, passim.

${ }^{44}$ PADFIELD, Nicola y MARUNA, Shadd, "The revolving door at the prison gate: Exploring the dramatic increase in recalls to prison", Criminology and criminal justice, vol. 6, $\mathrm{n}^{\circ} 3$ (2006), pp. 329-352 passim.

${ }^{45}$ MUNDEN, David P., TEWKSBURY, Richard, y GROSSI, Elizabeth, "Intermediate Sanctions and the Halfway Back Program in Kentucky", Criminal Justice Policy Review September, vol. 9, nº 3 (1999), pp. 431449, passim.

${ }^{46}$ GLAZE/BONCZAR, "Bureau of Justice Statistics", cit. nota no 8, passim.

${ }^{47}$ SABLE, W.J. y COUTURE H., Prison Inmates at Midyear 2007, Washington, DC: Bureau of Justice Statistics, 2008, passim.

${ }^{48}$ GRATTET, Ryken; PETERSILIA, Joan, LIN, Jeffrey y BECKMAN, Marlene, "Parole Violations and Revocations in California: Analysis and Suggestions for Action", Federal Probation, vol. 73, no 1 (2009), pp. 2-11, passim.

${ }^{49}$ SIMON, Poor Discipline, cit. nota ${ }^{\circ} 16$, passim.

${ }^{50}$ WODAHL/OGLE/HECK, "Revocation trends", cit nota n ${ }^{\circ} 39$, passim.
} 
Polít. crim. Vol. 9, № 17 (Julio 2014), Art. 5, pp. 147-181.

[http://www.politicacriminal.cl/Vol_09/n_17/Vol9N17A5.pdf]

argumentan que el incremento progresivo de las tasas de reingresos a la prisión representa la mayor amenaza a la actual percepción de legitimidad de las CSM hoy en día. La percepción es que estas sanciones "alterativas" al encarcelamiento son incapaces de realizar su trabajo sin recurrir a la misma pena privativa de libertad. En efecto, una consecuencia irónica del giro managerialista en las CSM es que, mientras la tendencia es motivada y estimulada por una marcada aversión al riesgo y de "gestión de la imagen" [impression management ${ }^{*}$, el mismo aspecto managerialista ha sido objeto de constantes críticas tanto de parte de los políticos, como de los practicantes y del público en general. Por un lado, los indicadores de desempeño "managerialistas" que tienen poca o ninguna relación con la calidad de la supervisión han sido objeto de críticas, por ejemplo como ha ocurrido recientemente en las jurisdicciones del Reino Unido. ${ }^{51}$ Por otro lado, a pesar del carácter más intrusivo y exigente (para aquellos supervisados) de las actividades conjuntas de gestión de riesgos de la policía y de lo servicios de libertad condicional, poco consuelo parece ofrecer a un público que se siente inseguro. Parece claro que situaciones de fracaso, independientemente de si es por una causa sistémica o no, tienden a atraer publicidad significativamente adversa y por tanto amenazan la legitimidad de las CSM. ${ }^{52}$

\section{Sanciones en comunidad "Punitivas".}

Para muchos de los defensores de las CSM, quizás especialmente dentro de las jurisdicciones europeas, la idea de sanciones en comunidad punitivas es un anatema. Tradicionalmente, estas sanciones han estado asociadas no sólo con una forma de manifestación del estado de bienestar, sino que también como una forma de evitar el castigo del Estado. Por ejemplo, la ley de probation establecida en Inglaterra y Gales por la "Ley de Probation de Infractores de 1907" gozó del status legal de una alternativa al castigo. Dicho eso, tales "alternativas" han involucrado siempre el ejercicio de poder y control sobre otros individuos, no obstante ser una forma más "blanda" de control que la prisión. Siguiendo el argumento de Foucault ${ }^{53}$ en lo relativo al "poder de normalización", Garland $^{54}$ ha hecho notar que el nuevo régimen de la probation establecido en la primera parte del siglo XX representa tanto una respuesta más "humana" al delito, como también una "red de control" más amplia y sutil. Las CSM también han tenido la tendencia de

\footnotetext{
${ }^{*}$ N. del T.: El concepto de "Impression Management" es propio de la sociología y la psicología social. Aún cuando es posible traducirlo a "gestión de la impresión" dicha traducción resultaría imprecisa. Usualmente el término se refiere al acto de intentar influir sobre la percepción que terceros poseen de uno mismo.

${ }^{51}$ NATIONAL AUDIT OFFICE, National Probation Service: The supervision of Community Orders in England and Wales, Londres: TSO, 2008. Ver también CHAPMAN, Tim, "Revising the national outcomes and standards for criminal justice social work services in Scotland", en: McNEILL, Fergus, RAYNOR, Peter y TROTTER, Chris, Offender Supervision: New Directions in Theory, Research and Practice, Cullompton: Willian, 2010, pp. 430-450.

52 ROBINSON, Gwen y McNEILL, Fergus, "Purposes matter: examining the "ends" of probation practice", en: MAIR, George (Ed.), What matters in probation, Cullompton: Willian, 2004, pp. 277-304. También McCULLOCH, Trish y McNEILL, Fergus, "Consumer Society, commodification and offender management", Criminology and Criminal Justice, vol. 7, $\mathrm{n}^{\circ} 3$ (2007); asimismo McNEILL, Fergus, "Probation, credibility and justice", Probation Journal, vol. 58, $\mathrm{n}^{\circ} 1$ (2011), pp. 9-22, y FITZGIBBON, Wendy, Probation and Social Work on Trial, London: Palgrave Macmillan, 2011.

${ }_{53}^{53}$ FOUCAULT, Michel, Discipline and punish: The Birth of Prison, Londres: Allan Lane, 1975/1977.

${ }^{54}$ GARLAND, Punishment and Welfare, cit. nota $\mathrm{n}^{\mathrm{o}} 17$, passim.
} 
ROBINSON, Gwen; McNEILL, Fergus; MARUNA, Shadd. "Castigo en sociedad: La Improbable persistencia de la probation y otras sanciones y medidas comunitarias".

encontrarse respaldadas por la posible imposición de una sanción privativa de libertad si el infractor incurre en algún incumplimiento de las condiciones establecidas. ${ }^{55}$

Desde nuestra perspectiva creemos que es ingenuo sugerir que las CSM contemporáneas carecen de una dimensión punitiva. Más que encontrarse implícito y escondido, como ocurría quizás en épocas anteriores, en algunas jurisdicciones la exhibición explícita de "credenciales punitivas" por parte de las CSM se ha convertido en una pieza clave en la búsqueda por legitimarlas en los sistemas penales de la modernidad tardía. Esto debe ser comprendido en el contexto de, al menos, tres procesos o desarrollos que han impactado significativamente a las CSM desde los años 80.

Los primeros dos se encuentran vinculados con los procesos de "managerialización" discutidos en la sección anterior. El primero es el objetivo sistémico de "reduccionismo penal": ${ }^{56}$ específicamente la idea de que sólo las sanciones punitivas son percibidas por los jueces como alternativas creíbles a las sanciones privativas de libertad. Quizás la transformación más obvia relacionada con este punto es la introducción en varias jurisdicciones de nuevas leyes que requieren que los sujetos realicen trabajos gratuitos o "servicio comunitario", aunque, como discutiremos más adelante, la identidad punitiva de dichas medidas eran a menudo confusas debido a su potencial rehabilitador. ${ }^{57}$ El segundo de estos acontecimientos se trata de la inclusión, por parte de algunos estados de Estados Unidos durante los años 70, de sistemas de determinación de la pena basados en la retribución o justo merecimiento de la misma, ejemplo que fue seguido por otras jurisdicciones internacionales en las décadas siguientes. En este sentido, como varios comentaristas han hecho notar, el giro hacia el retribucionismo como teoría de la pena predominante se encuentra, en parte, explicada por la búsqueda managerialista de metas y objetivos "realizables en la práctica" (en este caso distribuyendo el castigo en proporción al comportamiento criminal), aunque existen otros motivos significativos detrás de éste giro. ${ }^{58}$ La búsqueda sistémica del justo merecimiento de la pena por actos criminales, requirió necesariamente de un análisis acerca de todos los tipos de sanciones en función de su contenido retributivo, o "peso punitivo". Así, en este contexto, las CSM fueron reconceptualizadas y calibradas junto a un nuevo "continuum punitivo" dentro del cual eran vistas como "duras" y como sanciones relativamente baratas para aquellos culpables de delitos menos graves. ${ }^{59}$ En este contexto, se puede sostener que el potencial constructivo de las CSM se volvió menos importante que sus cualidades retributivas, las que pueden ser medidas en su alcance, intensidad y capacidad intrusiva.

El tercer, y el más reciente, conductor de las sanciones en comunidad punitivas, ha sido la politización del delito y de la justicia criminal, y el aumento de la necesidad de recurrir, por parte de los políticos y encargados de crear políticas públicas, al "populismo punitivo" o

\footnotetext{
${ }^{55}$ RAYNOR/VANSTONE, “Towards a correctional service”, cit. nota n ' 35, passim.

${ }^{56}$ CAVADINO/DIGNAM, The Penal system, cit nota $\mathrm{n}^{\circ} 31$, passim.

${ }^{57}$ McIVOR, Gill, "Paying back: 30 years of unpaid work by offenders in Scotland", European Journal of Probation, vol. 2, no 1 (2010), pp. 41-61, passim.

${ }^{58}$ BOTTOMS, "The philosophy and politics", cit. nota $n^{\circ} 25$, passim y GARLAND, "The limits", cit. nota $n^{\circ}$ 25, passim.

${ }^{59}$ MORRIS, Norval y TONRY, Michael, Between prison and probation: Intermediate Punishments in a Rational sentencing System, Oxford: Oxford University Press, 1990, passim.
} 
Polít. crim. Vol. 9, № 17 (Julio 2014), Art. 5, pp. 147-181.

[http://www.politicacriminal.cl/Vol_09/n_17/Vol9N17A5.pdf]

"populismo penal". ${ }^{60}$ En este escenario, la tradicional CSM de rehabilitación se ha encontrado con la crítica por ser demasiado "blanda" o alineada con las necesidades y/o intereses de aquellos condenados por delitos, en vez de con la "mayoría respetuosa de la ley" o las víctimas de los delitos. ${ }^{61}$ De manera significativa, desde que la rehabilitación, en sí misma, fue vista como "demasiado blanda", al considerar a los probationers como desvalidos y necesitados de ayuda o tratamiento, las sanciones convencionalmente vestidas con el ropaje de la rehabilitación fueron desvestidas y despojadas de su legitimidad, dejadas en necesidad de un nuevo atuendo ${ }^{62}$.

Estos tres acontecimientos claves, cada uno por si solo o en conjunto, tienen sentido de giro punitivo en el contexto de las CSM, donde se ha podido observar la creación y generación de una nueva "marca" de CSM intensivas con una orientación explícitamente punitiva o retributiva. Un ejemplo de esto fue el movimiento Estadounidense de sanciones "intermedias", que vio emerger, durante los años 80 y 90, el servicio comunitario, la supervisión intensiva, el arresto domiciliario, reportes diarios en centros, y los programas llamados "Boot Camps"*63 son prueba de esto, así como también lo es la imposición a los probationers y a los parolees del pago de una cuota por el costo de su propia supervisión. ${ }^{64}$ Otro ejemplo es la tendencia hacia la "combinación creativa" de múltiples condiciones o requerimientos como parte de una sola sanción, como ha sido observado en Inglaterra y Gales $^{65}$. En efecto, en ambos países una plétora cantidad de sanciones en comunidad separadas han sido recientemente fusionadas en un solo cuerpo genérico denominando "community order", el que permite a los sentenciadores seleccionar cualquier combinación de condiciones de un "menú" de doce diferentes requisitos y restricciones. ${ }^{66}$

Como hemos observado más arriba, muchas jurisdicciones han atestiguado una baja tolerancia respecto de los "incumplimientos de las condiciones" o la violaciones de la CSM, lo que puede decirse es otro correlato del giro punitivo de las CSM. ${ }^{67}$ Otro ejemplo

\footnotetext{
${ }^{60}$ Lo que tiene su fundamento, al menos en parte, en una mala lectura de la opinión pública en lo que se relaciona al sistema de justicia penal. Ver ROBERTS, Julian V. y HOUGHT, Mike, "Custody or community? Exploring the boundaries of public punitiveness in England and Wales", Criminology and Criminal Justice, vol. 11, no 2 (2011), pp. 181-197. Sobre el populismo punitivo y el populismo penal ver BOTTOMS, "The philosophy and politics", cit. nota $\mathrm{n}^{\circ} 25$, passim y PRATT, John, BROWN, David y BROWN, Mark, The New Punitiveness: Trends, Theories, Perspectives, Cullompton: Willian, 2005, passim.

${ }^{61}$ HOME OFFICE, Rebalancing the criminal justice system in favour of the law-abiding majority: Cutting Crime, Reducing Re-offending and Protecting the Public, Londres: Home Office, 2006, passim.

${ }^{62}$ MARUNA, Shadd, LEBEL, Thomas P., "Welcome Home? Examining the "Reentry Court" Concept from a Strengths-based Perspective", Western Criminology Review, Vol. 4, nº 2 (2003), pp. 91-107, passim.

* N. del T.: Los "Boots Camps" son programas basados en la estructura de los servicios de entrenamiento militares estadounidenses.

${ }^{63}$ TONRY/LYNCH, "Intermediate Sanctions", cit. nota n ${ }^{\circ} 41$, passim.

${ }^{64}$ DILLER, Rebekah; GREENE, Judith; JACOBS, Michelle, Maryland's Parole Supervision Fee: A Barrier to Reentry, New York: Brennan Center for Justice, 2009, passim.

${ }^{65}$ BOTTOMS/REX/ROBINSON, "How did we get here?", cit. nota $\mathrm{n}^{\circ} 43$, passim.

${ }^{66}$ MAIR, George; CROSS, Noel; TAYLOR, Stuart, The use and impact of the Community Order and the Suspended Sentence Order, Londres: Centre for Crime and Justice Studies, 2007, passim.

${ }^{67}$ ROBINSON, Gwen y McNEILL, Fergus, "Exploring the dynamics of compliance with community penalties", Theoretical Criminology, vol. 12, no 4 (2008), pp. 431-449, passim.
} 
ROBINSON, Gwen; McNEILL, Fergus; MARUNA, Shadd. "Castigo en sociedad: La Improbable persistencia de la probation y otras sanciones y medidas comunitarias".

reciente, que discutiremos más adelante, es la punitivización ${ }^{68}$ del trabajo en los servicios comunitarios a través de diversas formas de "estigmatización vergonzosa". ${ }^{99}$ En el Reino Unido y en otras jurisdicciones, las innovaciones tecnológicas también han sido utilizadas para incrementar la "mordida punitiva" de las CSM, o para incrementar el nivel de restricciones impuestas a los probationers en la comunidad. En el desarrollo del monitoreo electrónico (en adelante, "EM") ha sido notable cuan poca atención se le ha dedicado, pese a la existencia de ciertas investigaciones que aportan evidencia, en dicho sentido, al rol que el EM puede jugar en una supervisión más constructiva o rehabilitadora. ${ }^{70}$

En gran medida, el "giro punitivo" de las CSM se ha dado en un escenario donde ha sido conducido por buenas intenciones liberales para reducir el uso de las penas privativas de libertad. ${ }^{71}$ No obstante, la ausencia de una intención punitiva no implica, o no equivale, la ausencia de la "mordida penal" desde la perspectiva de quienes son objeto una sanción más intensiva en la comunidad. En efecto, en los años recientes se ha visto el surgimiento del interés entre los investigadores de una variedad de jurisdicciones en evaluar y analizar la penalidad relativa, depravaciones o "dolores" de las sanciones en comunidad de diferente tipo. $^{72}$ Por ejemplo, investigadores de la RAND Corporation en Estados Unidos encontraron que existían sanciones intermedias que los prisioneros entrevistados equiparaban con la prisión, en términos de castigo. Para algunos individuos, las formas intensivas de probation "pueden convertirse en las sanciones más temidas". 73 Más recientemente Durnescu específicamente ha explorado el dolor en la probation de Rumania. $^{74}$

Entonces, es claro que la evolución de las CSM en los sistemas penales de la modernidad tardía ha estado caracterizada por un incremento en la importancia de su "peso punitivo", y que esto ha sido una parte significativa de la búsqueda por legitimidad. No obstante, algunos críticos han argumentado que la narrativa detrás de esta aproximación "endurecedora" hace las CSM sería inherentemente contraproducente. Un hecho implícito en la premisa de las CSM punitivas es que el individuo condenado a estas medidas restrictivas es demasiado malo, peligroso y riesgoso para que se le impongan una CSM

\footnotetext{
${ }^{68}$ MARUNA, Shadd y KING, Anna, "Selling the Public on Probation: Beyond the Bib", Probation Journal, vol. 55, no 4 (2008), pp. 337-351, passim.

${ }^{69}$ BRAITHWAITE, John, Crime, Shame and Reintegration, Cambridge: Cambridge University Press, 1989, passim.

${ }^{70}$ NELLIS, "Electronic monitoring", cit. nota $\mathrm{n}^{\mathrm{o}} 37$, passim.

${ }^{71}$ MORRIS/TONRY, "Between prison and probation", cit. nota $\mathrm{n}^{\circ}$ 59, passim.

${ }^{72}$ SKYES, Gresham M., The Society of Captives: A Study of a Maximum Security Prison, Princeton, New Jersey: Princeton University Press, 1958, passim.

${ }^{73}$ PETERSILIA, Joan R., y DESCHENES, Elizabeth, "Perceptions of punishment: Inmates and staff rank the severity of prison versus intermediate sanctions", The Prison Journal, vol. 74, no 3 (1994), pp. 306. Ver también, PETERSILIA, Joan R., "When probation becomes more dreaded than prison", Federal Probation, vol. 54 (1990), pp. 23-27, también PAYNE, Brian K., y GAINEY, Randy R., "A Qualitative Assessment of the Pains Experienced on Electronic Monitoring", International Journal of Offender Therapy and Comparative Criminology, vol. 42, $\mathrm{n}^{\circ} 2$ (1998), pp. 149-163, passim y MAY, David, WOOD, Peter B., Ranking Correctional Punishments: Views from Offenders, Practitioners, and the Public, Durham, North Carolina: Carolina Academic Press, 2010, passim.

${ }^{74}$ DURNESCU, Ioan, "Pains of Probation: Effective Practice and Human Rights", International Journal of Offender Therapy and Comparative Criminology, vol. 55, $\mathrm{n}^{\circ} 4$ (2011), pp. 530-545, passim.
} 
Polít. crim. Vol. 9, № 17 (Julio 2014), Art. 5, pp. 147-181.

[http://www.politicacriminal.cl/Vol_09/n_17/Vol9N17A5.pdf]

ordinaria. Pero, si son tan peligrosos, los sentenciadores y opinión publica podrían preguntarse perfectamente ¿Entonces porque no se encuentran en prisión? La CSM simplemente no puede competir con los barrotes, las altas murallas, los alambres de púas de la prisión cuando se trata de proteger al público de los peligrosos. ${ }^{75}$

En las dos siguientes secciones, vamos a examinar dos estrategias más constructivas que han sido utilizadas para fortalecer la legitimidad de las CSM, esencialmente como formas de "castigo civilizado"; En concreto, el resurgimiento de la rehabilitación y los desarrollos en torno a la reparación.

\section{Sanciones en comunidad "rehabilitadoras"}

Históricamente, los profesionales de la probation, en la mayoría de las jurisdicciones, han comprendido que su función y su trabajo se encuentran mucho más relacionados con el trabajo social y el modelo de un estado de bienestar que con la justicia criminal. Aun así, el ideal de la rehabilitación, tan central a esta tradición, cayo públicamente en desgracia en los años $70,{ }^{76}$ y las CSM fueron rápidamente reorientadas - como hemos podido apreciar en las secciones anteriores - hacia aproximaciones más managerialistas y/o más punitivas. Los rumores de la muerte de la rehabilitación, no obstante, resultaron ser altamente exagerados, pues el ideal de la rehabilitación resurgió durante la última parte de los años 80 en la forma del movimiento "What Works" ["¿Que funciona?”]. ${ }^{77}$ Encabezado por un colectivo de investigadores asociados a los servicios correccionales de Canadá, que difundieron sus ideas a través de una serie de conferencias y talleres que contaron con la participación tanto de académicos como de profesionales, el "What Works" ha sido una historia de éxito global. Así, uno de los académicos que se encuentra en la primera línea de éste movimiento señaló:

"Hace tres décadas atrás, era ampliamente aceptado por criminólogos y por quienes tenían a su cargo las políticas públicas que "nada funciona" para reformar a los delincuentes y que la rehabilitación estaba muerta como filosofía correccional guía. En contraste, hoy en día existe un enérgico movimiento para reafirmar la rehabilitación e implementar programas basados en principios de intervención efectiva. ¿Cómo ocurrió esto? Yo sostengo que el rescate de la rehabilitación fue una realidad contingente que surgió debido a los esfuerzos de un pequeño grupo de investigadores en criminología sin conexión entre ellos. ${ }^{78}$

Dejando de lado por un momento la mejor forma de dar cuenta de este éxito, la prueba de la redención de la idea de la rehabilitación, nos la entrega, por ejemplo, el estado de California el que, bajo la dirección de un gobernador republicano, reemplazó el nombre de su

\footnotetext{
${ }^{75}$ MARUNA/KING, "Selling the Public", cit. nota $n^{\circ}$ 68, passim.

${ }^{76}$ ALLEN, Francis A., The decline of the rehabilitative ideal: Penal Policy and social purpose, New Haven, Connecticut: Yale University Press, 1981, passim.

${ }^{77}$ McGUIRE, James, What Works: Reducing Reoffending, Chichester: Wiley, 1995, passim y ANDREWS, Donald y BONTA, James, The Psychology of Criminal Conduct, $2^{\mathrm{a}}$ edición, New Jersey: Anderson Publishing, 2010, passim.

${ }^{78}$ CULLEN, Francis, "The twelve people who saved rehabilitation: how the science of criminology made a difference", Criminology, vol. 43, nº 1 (2005), p. 1.
} 
ROBINSON, Gwen; McNEILL, Fergus; MARUNA, Shadd. "Castigo en sociedad: La Improbable persistencia de la probation y otras sanciones y medidas comunitarias".

"Departamento Correccional" con el redundante nuevo título de "Departamento de corrección y rehabilitación”. Asimismo, la actual coalición de gobierno en el Reino Unido, dirigida por el Partido Conservador (Infame durante mediados de los 90 por iniciar un "giro punitivo" en las políticas públicas penales en torno al argumento de que "la prisión funciona") se encuentra promoviendo algo que se ha denominado "revolución de la rehabilitación". ${ }^{79}$ Estos son hitos notables considerando que por gran parte de las tres décadas pasadas la "rehabilitación" fue vista como una especie de concepto peyorativo, ${ }^{80}$ sobre todo entre los de la derecha política. ${ }^{81}$

Cullen $^{82}$ tiene razón cuando señala que el renacimiento de la rehabilitación en los sistemas penales contemporáneos debe mucho a los esfuerzos de los investigadores en criminología que rechazaron aceptar que nada podía hacerse para cambiar el comportamiento de los infractores de ley. Sin embargo, desde nuestra perspectiva aquello sólo es parte de la historia, y no podemos pasar por alto las formas en que la rehabilitación ha sido transformada y re-comercializada en el contexto de lo que es la penalidad de la modernidad tardía, de tal manera que lejos de ir "contra la corriente" de desarrollos mayores del sistema penal, se ha vuelto compatible con ellos. Como uno de nosotros ha sostenido previamente, es más preciso hablar de la "evolución" de la rehabilitación que de su sobrevivencia o renacimiento, por cuanto estos dos últimos términos implican, de alguna forma, una imagen algo estática (e imprecisa). ${ }^{83}$ Este proceso evolutivo ha creado visiones y formas de rehabilitación en el contexto de las CSM que divergen de previas encarnaciones, de formas importantes, como describiremos a continuación.

En primer lugar, la "nueva" rehabilitación ha tenido que adaptarse social y políticamente a contextos que se han vuelto cada vez más intolerantes a las aproximaciones e intervenciones que aparentemente ponen las necesidades e intereses de los infractores de ley por sobre los de las, reales y potenciales, víctimas. Los partidarios de la rehabilitación en jurisdicciones han sido objeto de "populismo punitivo" (ver más arriba) por lo que han debido desenfatizar sus justificaciones sociales, humanitarias y esencialmente centradas en el infractor de ley, a favor de otras racionalidades que enfatizan el carácter instrumental y ampliamente utilitario del valor rehabilitador de las sanciones. David Garland, ${ }^{84}$ fue uno de los primeros en observar este realineación de la rehabilitación en los Estados Unidos, e Inglaterra y Gales cuando hizo notar que el equipo del sistema correccional ahora enfatizaba que la "rehabilitación" es necesaria para la protección del público. Son las futuras víctimas las que deben ser "rescatadas" por el fruto del trabajo de rehabilitación, en vez de los infractores mismos. Esta idea de que la legitimidad de la rehabilitación contemporánea está en manos de una justificación utilitarista, ${ }^{85}$ ayuda a comprender tanto

\footnotetext{
${ }^{79}$ MINISTRY OF JUSTICE, Breaking the Cycle: Effective punishment, rehabilitation and sentencing of offenders, Londres: Ministry of Justice, 2010, passim.

${ }^{80}$ WARD, Tony y MARUNA, Shadd, Rehabilitation, Londres: Routledge, 2007, passim.

${ }^{81}$ FARABEE, David, Rethinking rehabilitation: Why can't we reform our criminals?, Washington: American Enterprise Institute Press, 2005, passim.

${ }^{82}$ CULLEN, "The Twelve", cit. nota no 78, passim.

${ }^{83}$ ROBINSON, Gwen, "Late-modern rehabilitation: the evolution of a penal strategy", Punishment and Society, vol.10, no 4 (2008), pp. 429-445, passim.

${ }^{84}$ GARLAND, "Probation", cit. nota n' 1, p. 6.

${ }^{85}$ ROBINSON, "Late-Modern", cit. nota $n^{\circ} 83$, passim.
} 
Polít. crim. Vol. 9, № 17 (Julio 2014), Art. 5, pp. 147-181.

[http://www.politicacriminal.cl/Vol_09/n_17/Vol9N17A5.pdf]

la difusión de los programas debajo de la bandera de lucha del movimiento "What Works" y el resurgimiento del interés y la inversión monetaria, en diversas jurisdicciones en la reinserción social de los ex convictos. ${ }^{86}$ Lo que a simple vista aparece como un indicador de una alta preocupación por el bienestar social y la reintegración de ex convictos o el deseo de reparar las perniciosas consecuencias del encierro, no obstante, se podría decir que obedece más a una expresión de preocupación por las comunidades a las cuales la mayoría de los ex convictos deben regresar y donde deben retomar sus vidas. ${ }^{87}$ En el Reino Unido, por ejemplo, se cree que los ex prisioneros son los autores de alrededor de 1 millón de delitos al año, costando alrededor de 11 billones de libras esterlinas anualmente. ${ }^{88}$

La segunda adaptación importante es que la rehabilitación ha comenzado a ser entendida menos como un medio en sí mismo y más como un medio para alcanzar un fin en los sistemas penales de la modernidad tardía. ${ }^{89}$ Específicamente, la rehabilitación se ha entendido como parte de un "grupo de herramientas" de medidas orientadas a la protección del público y de la gestión o administración del riesgo. Un desarrollo relacionado con esto, ha sido el reposicionamiento de las medidas rehabilitadoras al interior de los sistemas managerialistas, que han sido dominados por el discurso del riesgo. Sobre este aspecto, la rehabilitación no sólo ha devenido en ser concebida como un medio para obtener la meta que es la reducción del riesgo o su gestión, sino que también, cada vez más es racionada de acuerdo con las evaluaciones de riesgo que determinan la idoneidad de los infractores para los "nuevos" programas. Dicha aproximación asegura un espacio a la rehabilitación entre un rango de respuestas legítimas al delito, pero limita su alcance e influencia en nuevas formas.

Una de las mejores ilustraciones de esta diferenciada aproximación basada en el riesgo, es un modelo de aplicación de la probation introducido en Inglaterra y Gales en el año $2005 .^{90}$ Este supuesto "Offender management model" ["modelo de administración de infractores de ley"] utiliza la lógica del riesgo para determinar el nivel de recursos apropiados a destinar para cada infractor de ley; incrustado dentro de este modelo se encuentra una estructura compuesta de niveles, correspondiente a 4 tipos o estilos independientes de intervenciones, respecto de los cuales, al infractor sometido a supervisión por ley, le será asignado uno. Estos niveles se denominan "castigo", "ayuda", "cambio", y "control", y representan diferentes reacciones según la gravedad del perfil de riesgo del infractor. Únicamente el tercer nivel "cambio" contiene un elemento explícitamente disciplinario o de rehabilitación, y está dirigido a aquellos infractores cuyo riesgo de reincidencia es medio/alto. Este modelo

\footnotetext{
${ }^{86}$ MARUNA, Shadd; IMMARIGEON, Russ, After Crime and punishment: Pathway to offender reintegration, Cullompton: Willan, 2004, passim. Así también TRAVIS, Jeremy, But they all come back: facing the challenges of prisoner reentry, Washington, DC: The Urban Institute Press, 2005, passim y FARRAL, Stephen y SPARKS, Richard, "Introduction", Criminology and criminal justice, vol. 6 n 1 (2006), pp. 7-17, passim.

${ }^{87}$ WARD/MARUNA, Rehabilitation, cit nota $\mathrm{n}^{\circ}$ 80, passim y WACQUANT, Loïc, "Prisoner reentry as myth and ceremony", Dialectical Anthropology, vol. 34, n 4 (2010), pp. 605-620, passim.

${ }^{88}$ SOCIAL EXCLUSION UNIT, Reducing re-offending by ex prisoners, Londres: Home Office, 2001.

${ }^{89}$ GARLAND, "Probation", cit. nota $\mathrm{n}^{\mathrm{o}} 1$, passim y GARLAND, The Culture of Control, cit. nota $\mathrm{n}^{\mathrm{o}} 18$, passim.

${ }^{90}$ NATIONAL PROBATION SERVICE, National Probation Service: The supervision of Community Orders in England and Wales. Londres: TSO, 2005, passim.
} 
ROBINSON, Gwen; McNEILL, Fergus; MARUNA, Shadd. "Castigo en sociedad: La Improbable persistencia de la probation y otras sanciones y medidas comunitarias".

evidentemente actual ilustra de forma clara, que las intervenciones rehabilitadoras contemporáneas se encuentran lejos de ser adversas a los sistemas managerialistas.

No obstante, el encuadrar a la rehabilitación en los términos de manejo de riesgo y su régimen, no ha implicado simplemente darle un "giro" al mismo antiguo producto. Es importante destacar que, el producto en sí mismo, se ha adaptado como consecuencia del proceso evolutivo que hemos descrito. Es probablemente imprudente el caracterizar la rehabilitación contemporánea de las CSM como si fueran un producto unificado, por lo menos parece justo poder decir que dentro del rango de las CSM contemporáneas, los que son más explícitamente "rehabilitadores" son aquellos programas que apuntan al comportamiento de los infractores, los que surgieron bajo la bandera del movimiento "What Works", liderado principalmente por investigadores y profesionales correccionales de Canadá y del Reino Unido. Sobre la base de principios y métodos cognitivoconductuales, los nuevos programas enfocados en el comportamiento de los infractores proliferaron y se difundieron en los años 90, particularmente en las jurisdicciones angloparlantes y el norte de Europa, a la luz de la evidencia (de proyectos experimentales y sus "pruebas", por ejemplo Ross, Fabiano y Ewles ${ }^{91}$ ) sobre su efectividad técnica en reducir la reincidencia y contribuir a la seguridad pública. Varios gobiernos convocaron expertos en "paneles de acreditación", de manera de asegurar que los programas que iban a recibir fondos públicos estuvieran basados en la evidencia y conforme a los diseños y principios del servicio promovidos por los investigadores claves del movimiento "What Works?".92

Sin embargo, algunos han sostenido que no debemos atribuir la legitimidad de los programas rehabilitadores únicamente a su efectividad instrumental (putativa). Para algunos académicos, el dominio de los programas cognitivo-conductuales en algunas jurisdicciones es por lo menos en parte atribuible a sus cualidades expresivas y comunicativas y a su repercusión con formas liberales avanzadas de gobernanza que enfatizan en la responsabilidad personal por los delitos, y se basan en estrategias de "responsabilización" como respuesta dominante a la conducta antisocial. ${ }^{93}$ Lo mismo se ha dicho del resurgimiento contemporáneo de las aproximaciones de la justicia restaurativa, que son parte central de las CSM, por lo menos en algunas jurisdicciones en África, Europa y Norteamérica. ${ }^{94}$ Ambos modos de intervención buscan enfrentar a los infractores de ley con un "discurso moral" que por un lado comunica censura y por otro busca infundir en el infractor cierto grado de empatía con la víctima y como también una nueva "brújula moral"

\footnotetext{
91 ROSS, Robert R., FABIANO, Elizabeth A. y EWLES, Crystal D., "Reasoning and Rehabilitation", International Journal of Offender Therapy and Comparative Criminology, vol. 32, $\mathrm{n}^{\circ} 1$ (1988), pp 29-35, passim.

92 RAYNOR, Peter; ROBINSON, Gwen, Rehabilitation, Crime and Justice, Basingstoke: Palgrave Macmillan, 2009, passim.

${ }^{93}$ GARLAND, "The Limits of the Sovereign State", cit. nota $\mathrm{n}^{\circ} 25$, passim y ROSE, Nikolas, "Government and control", British Journal of Criminology, vol. 40, $\mathrm{n}^{\circ} 2$ (2000), pp. 321-339 y KENDALL, Kathleen, "Dangerous Thinking: A Critical History of Correctional Cognitive Behaviouralism" en: MAIR, George (Ed.), What Matters in Probation?, Cullompton, Devon, UK: Willan Publishing, pp. 53-89, passim.

94 DIGNAN, James, Understanding victims and restorative justice, Maidenhead: Open University Press, 2005, passim.
} 
Polít. crim. Vol. 9, № 17 (Julio 2014), Art. 5, pp. 147-181.

[http://www.politicacriminal.cl/Vol_09/n_17/Vol9N17A5.pdf]

por las cual, se espera, puedan disuadirlo de reincidir en el futuro. ${ }^{95}$ El infractor "rehabilitado", por lo tanto, es presentado como un individuo capaz de administrar sus propios riesgos sin tener que recurrir a sanciones o controles impuestos de forma externa, y sin tener que hacer ninguna demanda al estado en términos de deberes para crear oportunidades de reforma o reintegración. Así la rehabilitación es vista como un proyecto personal en vez de un proyecto social.

A pesar de existir cierta preocupación sobre el contenido abiertamente moralizante de los programas, los defensores de las CSM rehabilitadoras han tendido a ver esta proliferación y difusión de manera positiva. En jurisdicciones como Inglaterra y Gales, la "nueva rehabilitación" ha logrado captar considerables aportes monetarios de los gobiernos centrales ansiosos de capitalizar el potencial de dichas intervenciones para entregar protección al público mediante la vía de una reducción medible de la reincidencia por parte de los sujetos sometidos a tratamiento. Sin embargo, en la medida en que la legitimidad de las CSM rehabilitadoras estén en manos primariamente de justificaciones instrumentales, el futuro de las CSM está lejos de encontrarse asegurado. Puesto que los enfoques centradas en la protección del público no privilegian ninguna particular aproximación o tecnología, el fracaso para demostrar que se obtienen los resultados deseados (la reducción de la criminalidad), invita al uso de otras, potencialmente más "efectivas", aproximaciones del sistema penal; pero no menos incapacitadoras. ${ }^{96}$ Es en este sentido que Garland ${ }^{97}$ ha apuntado correctamente a la contingente legitimidad de la rehabilitación de la modernidad tardía, y que lo mismo puede decirse de la sanciones en comunidad rehabilitadoras de forma más genérica.

\section{Sanciones en comunidad "reparatorias".}

La vulnerabilidad de las CSM rehabilitadoras frente a su propia lógica instrumental sugiere la necesidad de buscar en otras direcciones por una fuente más segura y duradera de legitimidad. Anthony Bottoms escribió en 1980, cuando el renacimiento de la rehabilitación parecía algo improbable, que los sistemas penales debían prepararse para dar un giro en torno al ideal de la reparación. ${ }^{98}$ Bottoms destacó que un enfoque centrado en la reparación podría preservar la proporcionalidad central del modelo de justicia pero evitando las formas nocivas del castigo a favor de opciones más constructivas. Algunas veces la reparación puede centrarse en un particular tipo de víctima, otras veces puede estar dirigida a la comunidad. Él argumentaba que la rehabilitación puede ser un sub-producto de los esfuerzos puestos en la reparación, y que no necesita ser buscada directamente.

Las jurisdicciones respecto de las cuales Bottoms estaba escribiendo, (Inglaterra y Gales), han visto el comienzo del trabajo comunitario como una nueva forma independiente de sanción comunitaria disponible a lo largo del Reino Unido desde 1978, y esta nueva sanción se construye sobre una antigua tradición de aceptar trabajo no remunerado como

\footnotetext{
95 DUFF, Anthony, Punishment, Communications, and community, Oxford: Oxford University Press, 2001, passim.

${ }^{96}$ ROBINSON/McNEILL, "Purposes matter", cit. nota n” 52, passim.

${ }^{97}$ GARLAND, "Probation", cit. nota n' 1 , passim.

${ }^{98}$ BOTTOMS, “An Introduction”, cit. nota $\mathrm{n}^{\circ} 18$, passim.
} 
ROBINSON, Gwen; McNEILL, Fergus; MARUNA, Shadd. "Castigo en sociedad: La Improbable persistencia de la probation y otras sanciones y medidas comunitarias".

parte de la supervisión de las personas sometidas a probation. Pese a ello, en diversas jurisdicciones el trabajo comunitario "no ha sido ni única ni principalmente "comercializado" como una sanción reparatoria. Por ejemplo, esto se puede apreciar en los desarrollos de la nueva sanción en Escocia, McIvor explica sus variopintos propósitos de la siguiente forma:

"El servicio comunitario en Escocia pretendía cumplir con un número de objetivos de la sentencia, incluido el castigo (a través de privar al infractor de su tiempo libre), la rehabilitación (a través de los efectos positivos de ayudar a otros) y reparatorios (enfocando el trabajo para beneficiar a dichos grupos normalmente menos aventajados de la comunidad). El potencial reintegrador del trabajo comunitario pretendía lograrse al permitir que el infractor se mantuviera en la comunidad, manteniendo un empleo y sus lazos familiares, y, a través de entrar en contacto con otros mientras se realiza el trabajo gratuito, evitando el aislamiento social.",99

Junto a estos múltiples propósitos e identidades, el servicio comunitario o trabajo gratuito en diferentes lugares y tiempos ha tenido diferentes significados y funciones legales - como una sanción independiente o como parte de la supervisión de la probation, como una alterativa a la persecución penal o como una directa alternativa a la penas privativas de libertad o como una sanción autónoma por propio derecho. ${ }^{100}$

Aunque sus variados propósitos y usos han permitido su popularización de manera exitosa, en algunas jurisdicciones, al menos, esto también ha privado a los servicios comunitarios de una normativa narrativa clara, que parece necesaria ante el declive de la rehabilitación. En efecto, la popularización pragmática de los servicios comunitarios como una visión "de todo para todos", tal vez explica en parte por qué los vínculos entre éstos, los ideales de la reparación y de la justicia en comunidad han tendido a volverse más tenues de lo que eran en el pasado. Lo anterior, a pesar del hecho de que los análisis ofrecidos por Bottoms, ${ }^{101}$ Christie $^{102}$ y Hulsman, ${ }^{103}$ sostenían un acercamiento más enfocado en la víctima que borrase la distinción entre daños civiles y criminales, y buscase soluciones orientadas hacia las víctimas para las conductas dañosas, en vez del castigo. Bottoms esperaba que dichos argumentos y aproximaciones ganaran terreno, parcialmente por el aceptado análisis de Durkheim ${ }^{104}$ que sostiene que las sociedades más desarrolladas tenderían, cada vez más, a buscar compensar el desequilibrio entre el delincuente y la víctima, en lugar de limitarse a impartir sanciones contra el infractor. ${ }^{105}$

\footnotetext{
${ }^{99}$ McIVOR, "Paying back", cit. nota n' 57, p. 42.

${ }^{100}$ McIVOR, Gill, BEYENS, Kristel, BLAY, Ester y BOONE, Miranda, "Community service in Belgium, the Netherlands, Scotland and Spain: a comparative perspective", European Journal of Probation, vol. 2, $\mathrm{n}^{\mathbf{0}} 1$ (2010), pp. 82-98, passim.

${ }^{101}$ BOTTOMS, “An Introduction”, cit. nota no 18 , passim.

102 CHRISTIE, Nils, “Conflicts as property”, British Journal of Criminology, vol. 17, n 1 (1977), pp. 1-15, passim.

${ }^{103}$ HULSMAN, Louk, Strategies to reduce violence in society: civilising the criminal justice system, an address to the annual meeting of the Howard League for Penal Reform (unpublished), 1976, passim.

${ }^{104}$ DURKHEIM, Emile, "Two laws of penal evolution", Economy and Society, vol. 2 (1973), pp. 278-308.

105 BOTTOMS, “An Introduction” cit. nota $\mathrm{n}^{\mathrm{o}} 18$, pp. 16-17.
} 
Polít. crim. Vol. 9, № 17 (Julio 2014), Art. 5, pp. 147-181.

[http://www.politicacriminal.cl/Vol_09/n_17/Vol9N17A5.pdf]

Bottoms, ${ }^{106}$ también destacó que mientras la rehabilitación, por lo menos desde una lectura Foucualtiana, representaba (o por lo menos fue rápidamente reconducida a ello) un proyecto de coerción, y transformación, del "alma", una alternativa diferente al expresivo castigo pre-moderno que se ha identificado en el trabajo de los clásicos del siglo XVIII (como por ejemplo en Beccaria ${ }^{107}$ ) quienes sostendrían el uso del castigo como "una forma de recalificar a los individuos (...) como sujetos jurídicos". ${ }^{108}$ De manera crítica, la reparación - y el trabajo reparatorio en particular - parece capaz de cumplir esta función de formas en que la rehabilitación no puede, principalmente porque la rehabilitación de los infractores no enmienda per se; ésta opera sólo en el individuo, no en el conflicto mismo y tampoco en la víctima o en la comunidad. ${ }^{109}$

El problema de la rectificación (o la ausencia de tal), parece subyacer en recientes intentos de potenciar pública y judicialmente la confianza en las CSM. ${ }^{110}$ Tanto en Escocia como en Inglaterra y Gales, aunque de formas diferentes, las CSM se han centrado, en la noción de reparación o más específicamente en la idea del "payback".* Una reciente comisión escocesa sobre el estado de las prisiones, ${ }^{111}$ por ejemplo, sostuvo que el encarcelamiento debe descentralizarse de la concepción de castigo transformando la idea de retribuir o compensar a la comunidad la respuesta estándar del sistema penal. El parlamento escocés, en consecuencia, generó una ley (Denominada "The Criminal Justice and Licensing Act 2010") para renombrar casi todas las CSM como "Community Payback Orders". La comisión definió "payback" como:

"encontrar formas constructivas de compensar o reparar los daños causados por el delito. Esto supone compensar a la víctima y/o a la comunidad. Esto puede ocurrir a través de un pago económico, trabajo no remunerado, la participación en trabajo rehabilitador o alguna combinación de estos y otras aproximaciones."

La ley de Justicia Criminal y Permisos de 2010 es notable, por cuanto consagra una lógica reparatoria para casi todos los CSM, y no sólo respecto de aquellas relacionadas con el trabajo no remunerado. Como destaca la Comisión sobre el estado de las prisiones en

\footnotetext{
${ }^{106}$ BOTTOMS, “An Introduction” cit. nota n ${ }^{\circ} 18$, passim.

107 BECCARIA, Cesare, "On crimes and punishment”, Trad.: PALLOUCI, H., Indianapolis: Bobbs Merrill, 1963, passim.

${ }^{108}$ FOUCAULT, Discipline and punish, cit. nota $\mathrm{n}^{\circ}$ 53, p. 130.

109 ZEDNER, Lucia, “Reparation and Retribution: Are They Reconcilable?”, The Modern Law Review, Vol. 57, no 2 (1994), pp. 228-250, passim.

${ }^{110}$ Pat Carlen sostuvo que en algunas comunidades fracturadas y en situaciones de desventaja, las alternativas de justicia comunitaria simplemente no son "viables". CARLEN, Pat, "Crime, Inequality and Sentencing" en: CARLEN, Pat y COOK, Dee (Eds.), Paying for Crime, Milton Keynes: Open University Press, 1989, pp. 828, passim.

${ }^{*}$ N. del T. El término "Payback" en inglés puede aludir a pagar una deuda en dinero como también a la noción de venganza. En este contexto su uso adquiere un sentido ambiguo dentro del marco de las CSM. Por un lado implica un aspecto reparatorio, pero al mismo tiempo, le da un cariz punitivo a la sanción.

${ }^{111}$ SCOTTISH PRISONS COMMISSION, Scotland's Choice, Edinburgo: Scottish Prison Commission, 2008, passim.

${ }^{112}$ SCOTTISH PRISONS COMMISSION, Scotland's Choice, cit. nota 111, párrafo 3.28.
} 
ROBINSON, Gwen; McNEILL, Fergus; MARUNA, Shadd. "Castigo en sociedad: La Improbable persistencia de la probation y otras sanciones y medidas comunitarias".

Escocia, "una de las mejores formas para que los infractores puedan retribuir es enderezando sus vidas." $" 113$ El esfuerzo rehabilitador es visto como una forma de reparación.

La probabilidad de éxito de este tipo de estrategia de legitimación reparadora para las CSM es difícil de juzgar. Durante la misma época en que se hizo público el reporte de la Comisión Escocesa sobre el estado de las Prisiones, la oficina del Gabinete del Reino Unido publicaba el Reporte Casey sobre "La participación de las comunidades en la lucha contra el crimen", ${ }^{114}$ el cual proponía construir confianza pública en el "trabajo no remunerado" al re-etiquetarlo como "retribución en comunidad" ("Community payback") No obstante el concepto de Casey sobre "payback" es bastante diferente que el de la Comisión Escocesa. Ella sugirió que el trabajo a realizar no debiera ser algo que el común de la gente escogería hacer por sí mismos, esto es, labores poco placenteras y frustrantes, y que los individuos que realizan el "payback" debieran vestir ropa que los identificara ante todos como infractores, en otras palabras, que los avergonzara. ${ }^{115}$

Mirando más allá del servicio comunitario o el trabajo no remunerado, la reparación también ha sido importante y controvertido discurso para las CSM en otras jurisdicciones. Canton ${ }^{116}$ cita a Austria, Bélgica, Noruega y partes de Alemania como lugares en los que se ha desarrollado mediación víctima-infractor, y también destaca que en algunos de los nuevos servicios de probation europeos (por ejemplo los de la Republica Checa, Letonia y Turquía) han consagrado los principios de la reparación y mediación en sus estatutos de constitución. El trabajo reparatorio también ha jugado un rol significativo en sociedades en transición, a menudo como consecuencia de los esfuerzos por buscar la paz y la reconciliación en las comunidades. ${ }^{117}$ En Irlanda del Norte, por ejemplo, tiene uno de los sistemas base de justicia restaurativa en comunidad mejor desarrollados en el mundo. ${ }^{118}$ En la Sudáfrica post-apartheid, por otro lado, aunque los servicios de probation se han desarrollado rápidamente, la justicia reparativa está más en la marginalidad de este trabajo. ${ }^{119}$ En otras partes de África, sin embargo, las sentencias en comunidad tienden a enfocarse casi enteramente en servicio comunitario, lo que según Ehlkers, "encaja bien con sus tradiciones culturales de indemnizar por el daño causado". ${ }^{120}$

113 SCOTTISH PRISONS COMMISSION, Scotland's Choice, cit. nota 111, párrafo 33. Ver también McNEILL, "Probation, credibility and justice", cit. nota n ${ }^{\circ} 52$, passim.

${ }^{114}$ CASEY, Louis, Engaging Communities in Fighting Crime: A review, Londres: Cabinet Office, 2008, passim.

${ }_{115}$ MARUNA/KING, "Selling the Public", cit. nota 68, passim.

${ }^{116}$ CANTON, Rob, "Probation in Europe" en: CANTON, Rob; HANCOCK, David (Eds.), Dictionary of Probation and Offender Management, Cullompton: Willan, pp. 230-231.

117 ERIKSSON, Anna, Justice in Transition: Community Restorative Justice in Northern Ireland, Cullompton: Willian, 2009, passim.

${ }^{118}$ McEVOY, Kieran y MIKA, Harry, "Punishment, Policing and Praxis: Restorative Justice and Non-Violent Alternatives to Paramilitary Punishments in Northern Ireland", Policing and Society, vol. 11 (2001), pp. 359382, passim.

${ }^{119}$ ROCHE, Declan, "Restorative Justice and the Regulatory State in South African Townships", The British Journal of Criminology, vol. 42, $\mathrm{n}^{\circ} 3$ (2002), pp. 514-533; y EHLERS, Louise, "Probation in Africa" en: CANTON, Rob; HANCOCK, David (Eds.), Dictionary of Probation and Offender Management, Cullompton: Willian, 2007, pp. 228-229, passim.

${ }^{120}$ EHLERS, "Probation in Africa", cit. nota $\mathrm{n}^{\mathrm{o}} 119$, p. 229. Sobre el castigo en situaciones post-conflictos sociales ver McEVOY, Kieran y MALLINDER, Louise, "Amnesties, transitional justice and governing 
Polít. crim. Vol. 9, № 17 (Julio 2014), Art. 5, pp. 147-181.

[http://www.politicacriminal.cl/Vol_09/n_17/Vol9N17A5.pdf]

El movimiento de "justicia comunitaria" que se ha extendido desde los Estados Unidos ${ }^{121}$ hasta el Reino Unido ${ }^{122}$ también asigna un rol central a los objetivos de reparación, basados parcialmente en una lectura de la filosofía comunitarista de Amitai Etzioni. ${ }^{123}$ Si bien no existe una fórmula consensuada o estándar para lo que puede constituye la justicia comunitaria, ${ }^{124}$ Winstone y Pakes sugieren que ésta refleja tres principios claves:

"Primero, la comunidad es el consumidor final de la justicia criminal. Más que los infractores, o que las víctimas, es a las comunidades a las que el sistema debe servir. Segundo, la justicia comunitaria se logra en colaboración con el nivel local. Tercero, se centra en los problemas: Los problemas son abordados, más que procesados como casos" 125

Recientemente, los movimientos por la justicia comunitaria se han vuelto, tal vez, más influyentes a través del desarrollo de la "reinversión de justicia", un acercamiento esencialmente enfocado en los resolución de conflictos y que busca obtener que parte del presupuesto "correccional" se destine a incitativas de reducción de la criminalidad precisamente en aquellos vecindarios desde donde proviene la mayor cantidad de personas condenadas a penas privativas de libertad. ${ }^{126}$

\section{8. ¿Cuál es el futuro para el castigo en sociedad? Buscando legitimidad.}

Las sanciones de la justicia criminal ejecutadas en sociedad abierta representan particularmente un interesante caso de estudio para los estudiantes de "castigo y sociedad", después de todo, como nuestro título sugiere, las CSM representan una forma primaria del castigo en sociedad, en lugar de la extracción de la sociedad como forma de castigo. Un argumento clave de los análisis sociales de la penalidad es que nosotros podemos, en el rango de las sanciones penales, instituciones y prácticas, ver un reflejo del desarrollo social,

through mercy", en: SIMON, Jonathan; SPARKS, Richard (Eds.), The Sage Handbook of Punishment and Society, Londres: SAGE, 2013, pp. 434-462, passim.

${ }^{121}$ CLEAR, Todd, y KARP, David, The Community Justice Ideal: Preventing crime and achieving justice, Oxford: Westview Press, 1999; y KARP, David; CLEAR, Todd, What is community justice? Case Studies of restorative and community Justice, Boston: Pine Forge, 2002, passim.

${ }^{122}$ HARDING, John., "A Community Justice Dimension to Effective Probation Practice", The Howard Journal of Criminal Justice, vol. 39 (2000), pp. 132-149, y HARDING, John, "Which Way Probation? A Correctional or Community Justice Service?", Probation Journal, vol. 50, nº 4 (2003), pp. 369-373. También NELLIS, Mike, "Creating community justice" en: BALLINTYNE, Scott, PEASE, Kenneth y McLAREN, Vic (Eds.), Secure Foundations: Key Issues in Crime Prevention, Crime Reduction and Community Safety, Londres: Institute for Public Policy Research, 2000, pp. 67-86; y NELLIS, Mike, "Dim prospects: Humanistic Values and the fate of community Justice", en: WINSTONE, Jane y PAKES, Francis (Eds.), Community Justice: Issues for probation and criminal justice, Cullompton: Willian, 2005, pp. 33-51.

${ }^{123}$ ETZIONI, Amitai, A Responsive Society: Collected Essays on Guiding Deliberate Social Change, San Francisco, California: Jossey-Basee, 1991, passim.

${ }^{124}$ CLEAR/KARP, The Community Justice Ideal, cit. nota ${ }^{\circ} 121$, passim.

${ }^{125}$ WINSTONE, Jane y PAKES, Francis (Eds.), Community Justice: Issues for probation and criminal justice, Cullompton: Willian, 2005, p. 2.

${ }_{126}$ TUCKER, Susan y CADORA, Eric, "Justice Reinvestment: to invest in public safety by reallocating justice dollars to refinance education, housing, healthcare, and jobs", Ideas for an Open Society, vol. 3, n 3 (2003); Nueva York: Open Society Institute. Versión online disponible en: http://www.opensocietyfoundations.org/sites/default/files/ideas_reinvestment.pdf [Visitado 04.08.2013]. 
ROBINSON, Gwen; McNEILL, Fergus; MARUNA, Shadd. "Castigo en sociedad: La Improbable persistencia de la probation y otras sanciones y medidas comunitarias".

político y cultural. Nuestra explicación de las estrategias de adaptación sugiere que en ningún lugar del campo penal esto es más evidente que en las sanciones en comunidad, las que han probado ser extraordinariamente "elásticas" tanto en sus formas como en sus funciones a lo largo de su historia. Debido a la relación umbilical de la probation con el deteriorado proyecto del estado de bienestar penal, ${ }^{127}$ las sanciones en comunidad han estado involucradas durante los últimos 30 o 40 años en una lucha especialmente significativa por su legitimidad, ${ }^{128}$ una lucha que ha sido mucho más profunda para las sanciones ejecutadas en la comunidad que en la prisión (aun cuando las prisiones en varios países han experimentado una variedad de crisis de legitimación, por si mismas). ${ }^{129}$ Las sanciones en comunidad han tenido que adaptarse a nuevas condiciones sociales y políticas, ya no desde la "seguridad" de los muros de las prisiones, sino que desde el interior de la comunidad, expuesta a ésta y a la sociedad.

Como sostiene Joshua Page, ${ }^{130}$ las explicaciones de la penalidad y sus transformaciones requieren un análisis cuidadoso no sólo de las fuerzas sociales que operan en el campo (desde "afuera", si se quiere), sino que también de las relaciones y dinámicas desde "dentro" del campo penal, en sus variadas sub-áreas y en sus interacciones con otros campos de la acción social. Recurriendo al trabajo de Pierre Bordieu, Page delinea los contornos del campo penal, explicando las relaciones entre los hábitos o disposiciones de los actores del sistema penal y su titularidad y luchas por diversas formas de capital dentro y a través de la penalidad y sus campos de intersección. Aunque no lo hemos denominado principalmente de dicha manera, nuestro análisis de las adaptaciones de las CSM puede leerse como una explicación para una variada gama de formas en las cuales los "ejecutivos", profesionales y defensores de las CSM han buscado asegurar dicho capital en un campo penal cada vez más inestable, uno en que las CSM permanecen eternamente marginales e inseguras, pese a su proliferación. Diferentes formas de capital están siendo buscadas y pelean entre sí en los distintos intentos de asegurar la legitimidad que hemos esbozado.

Como Wodahl, Ogle y Heck ${ }^{131}$ han destacado recientemente, (siguiendo a Suchman ${ }^{132}$ ), diferentes tipos de legitimidad se encuentran en juego aquí: la legitimidad pragmática está en manos de la habilidad de las CSM de encontrar las necesidades de las partes interesadas;

${ }^{127}$ GARLAND, Punishment and Welfare, cit. nota $\mathrm{n}^{\mathrm{o}} 17$, passim.

${ }^{128}$ WEBER, Max, "Class, Status, Party” en: GERTH, H.H.; WRIGHT MILLS, C. (Eds.), From Max Weber: Essays in sociology, Nueva York: Oxford University Press, 1946, pp. 180-195 y SUCHMAN, Mark C., "Managing Legitimacy: Strategic and Institutional Approaches", The Academy of Management Review, Vol. $20, \mathrm{n}^{\circ} 3$ (1995), pp. 571-610, passim.

${ }^{129}$ Sobre este punto ver LIEBLING, Alison y CREWE, Ben, "Prisons beyond the new penology: The shifting moral foundation of prison Management", en: SIMON, Jonathan y SPARKS, Richard (Eds.), The Sage Handbook of Punishment and Society, Londres: SAGE, 2013, pp. 283-307, passim.

${ }_{130}$ PAGE, Joshua, "Punishment and inequality" en: SIMON, Jonathan y SPARKS, Richard (Eds.), The Sage Handbook of Punishment and Society, Londres: SAGE, 2013, pp. 169-185, passim.

${ }^{131}$ WODAHL/OGLE/HECK, "Revocation trends", cit. nota n' 39 , passim.

${ }^{132}$ Existen, por supuestos varias concepciones de legitimidad desde una amplia gama de disciplinas de las ciencias sociales. El análisis de Suchman, en el cual nos hemos basado, deriva del estudio de la literatura organizacional, más que de la literatura sociológica, psicológica o de las ciencias políticas respecto de las cuales los investigadores en criminología suelen basarse. Ver CRAWFORD, Adam; HUCKLESBY, Anthea, Legitimacy and Compliance in Criminal Justice, Londres: Routledge, 2012, passim. 
Polít. crim. Vol. 9, № 17 (Julio 2014), Art. 5, pp. 147-181.

[http://www.politicacriminal.cl/Vol_09/n_17/Vol9N17A5.pdf]

la legitimidad moral se relaciona con el compromiso para alcanzar las metas de conformidad con los valores sociales; la legitimidad cognitiva se presenta sólo cuando las acciones y funciones de una institución se encuentran tan entrelazadas con el entramado social que "simplemente tienen sentido" de tal forma que las "alternativas se vuelven impensables". ${ }^{133}$ Así, mientras el estado de bienestar penal comenzaba a ser eclipsado, el ideal rehabilitador perdía su legitimidad moral, socavando el progreso de las CSM para lograr tener una posición de "ser dadas por sentado" en el campo penal (esto es, su legitimidad cognitiva). Esto ha ocasionado una perdida de capital cultural y simbólico dado que las viejas formas de conocimiento y mérito se han devaluado. La búsqueda de nuevas formas de capital requiere que las CSM aprendan a "jugar el juego (penal)" con otras reglas; la adaptación managerialista descrita más arriba (irónicamente a veces llamada "modernización") representa un discurso por una legitimidad pragmática en un campo cambiante caracterizado por la reconfiguración de las necesidades de las partes interesadas (por ejemplo, el bajo costo de las alternativas a las penas privativas de libertad). Pero la politización de la justicia criminal cambió el juego nuevamente en al menos dos formas. Primero, la legitimidad pragmática se volvió insuficiente, las CSM necesitan responder a los valores penales cambiantes de la sociedad y la política ofreciendo la "mordida punitiva" que se espera asegure alguna "legitimidad moral". En términos de Bordieu, esto podría ser visto como un intento por coger el capital simbólico, lo que dependería de ser visto como suficientemente "duro" en la entrega de la "violencia simbólica" por y para el Estado sancionador (en términos de Bordieu). Segundo, amplias fuerzas sociales relacionadas con el riesgo y la inseguridad ha impulsado a las CSM hacia una forma diferente de legitimidad pragmática enraizada en la promesa de cumplir con las necesidades de protección de las partes interesadas. Aquí, el capital cultural y simbólico con el cual las CSM buscan negociar reside en las nuevas afirmaciones de experticia y de efectividad en torno al riesgo y a su gestión o administración.

La estrategia reparatoria es la variable atípica en esta lista. Es tal vez el desarrollo contemporáneo más interesante y, en nuestra opinión, la esperanza más brillante para el futuro de las CSM. Si hoy los defensores de las CSM reconocieran las vulnerabilidades de negociar con la promesa de proteger (una promesa que ellos jamás podrán entregar adecuadamente), podrían, en cambio, mirar hacia una estrategia reparatoria que parece teóricamente, por lo menos, ser potencialmente capaz de entregar tanto una legitimidad pragmática y moral - tanto una sanción rentable como compensatoriamente constructiva. ${ }^{134}$ Después de todo, las históricas formas pre-modernas y precedentes de la reparación sugieren recursos culturales profundos y duraderos ${ }^{135}$ que pueden de alguna manera ser explotados como nuevas formas de capital para las CSM. Tales formas de capital pueden, incluso, ser lo suficientemente confiables (debido a sus profundas raíces históricas y culturales) para permitir que las CSM logren ser "tomadas por sentadas", posición que le ha

\footnotetext{
${ }^{133}$ SUCHMAN, "Managing Legitimacy", cit. nota no 128 p. 583.

${ }^{134}$ El éxito o fracaso de las CSM reparatorias es evaluado principalmente en términos de cantidades, tipos y calidades de los actos reparatorios y no en términos de re-encarcelamiento. Las tasas de re-encarcelamiento "venden" sanciones en comunidad sobre la base de su rol en reducir el crimen. Centrarse en la reparación, no obstante, "vende" a las CSM en términos de entregar justicia (Ver McNEILL, "Probation", cit. nota n 52). Demostrar que la justicia se ha realizado, que aquella deuda ha sido zanjada, que aquella compensación ha sido entregada, son formas mucho mas fáciles y más alcanzables de medir el existo de las CSM.

${ }^{135}$ BRAITHWAITE, John; PETTIT, Philip, Not just deserts, Oxford: Oxford University Press, 1990, passim.
} 
ROBINSON, Gwen; McNEILL, Fergus; MARUNA, Shadd. "Castigo en sociedad: La Improbable persistencia de la probation y otras sanciones y medidas comunitarias".

sido esquiva y las ha condenado a vivir a la sombra de la prisión; siempre como una alternativa, nunca como la herramienta principal - o como nuestros editores Edimburgueses podrían decir "Siempre el "Fringe", nunca el festival"." Dicho esto, el Fringe de Edimburgo es más grande (algunos dicen), mejor, y quizás más rentable que el Festival, y ninguno de sus actores ni tampoco su audiencia podría tener cabida en el Festival. Lo mismo es verdad para las CSM con respecto a las prisiones. De una manera muy importante, por todos sus esfuerzos, la posición de las CSM podría ser simbólicamente frágil pero materialmente seguras, expresivamente insuficientes pero instrumentalmente necesarias. Las CSM sobrevivirán porque ellas deben sobrevivir; no podemos permitir ejercer (el castigo) sin ellas. Las preguntas acerca de sus adaptaciones que nosotros hemos puesto de relieve probablemente hablan más de las futuras formas y funciones de las CSM que de su longevidad. En cualquier evento, nosotros sugerimos que los penólogos presten mayor atención a observar su espacio, y no sólo a lo que ocurre al interior de los muros de la prisión.

\footnotetext{
136 "El Festival" aquí hace referencia al renombrado Festival Internacional de Edimburgo que se lleva a cabo en Escocia cada verano. El "Fringe" comenzó como un pequeño festival derivado hace alrededor de 50 años atrás, desde entonces ha crecido para convertirse en uno mucho más grande y variado que el Festival original, sin embargo su calidad varía entre lo sublime hasta lo francamente incompetente.
} 
Polít. crim. Vol. 9, № 17 (Julio 2014), Art. 5, pp. 147-181.

[http://www.politicacriminal.cl/Vol_09/n_17/Vol9N17A5.pdf]

\section{BIBLIOGRAFÍA}

ALLEN, Francis A., The decline of the rehabilitative ideal: Penal Policy and social purpose, New Haven, Connecticut: Yale University Press, 1981.

ANDREWS, Donald y BONTA, James, The Psychology of Criminal Conduct, $2^{\mathrm{a}}$ edición, New Jersey: Anderson Publishing, 2010.

BAUMAN, Zygmunt, Modernity and Ambivalence, Cambridge: Polity Press, 1991.

BAUWENS, Aline, "The transformation of offender rehabilitation", tesis doctoral, Bruselas: Vrije Universiteit, 2011.

BECCARIA, Cesare, "On crimes and punishment", Trad.: PALLOUCI, H., Indianapolis: Bobbs Merrill, 1963.

BELL, Daniel, The coming of post-industrial society, New York: Basic Books, 1973.

BETO, Dan R., CORBETT, Ronald P. y DILULIO, John J., "Getting serious about probation and the crime problem", Corrections Management Quarterly, no 4 (2000), pp. 1-8.

BOTTOMS, Anthony, "An introduction to the coming crisis", en: BOTTOMS, Anthony y PRESTON, Ronald H. (Eds.), The Coming Penal Crisis, Edimburgo: Scottish Academic Press, 1980, pp. 1-24.

, "The philosophy and politics of punishment and sentencing" en: CLARKSON,

Chris y MORGAN, Rod (Eds.), The politics of sentencing reform, Oxford: Clarendon Press, 1995, pp. 17-79.

BOTTOMS, Anthony, REX, Sue y ROBINSON, Gwen, "How did we get here?" en: BOTTOMS, Anthony, REX, Sue y ROBINSON, Gwen (Eds.), Alternatives to prison: Options for an insecure society, Cullompton: Willan, 2004, pp. 1-27.

BRAITHWAITE, John, Crime, Shame and Reintegration, Cambridge: Cambridge University Press, 1989.

BRAITHWAITE, John; PETTIT, Philip, Not just deserts, Oxford: Oxford University Press, 1990.

CANTON, Rob, "Probation in Europe" en: CANTON, Rob y HANCOCK, David (Eds.), Dictionary of Probation and Offender Management, Cullompton: Willan, 2007, pp. 230-231.

CARLEN, Pat, "Crime, Inequality and Sentencing” en: CARLEEN, Pat; COOK, Dee (Eds.), Paying for Crime, Milton Keynes: Open University Press, 1989, pp. 8-28.

CASEY, Louis, Engaging Communities in Fighting Crime: A review, Londres: Cabinet Office, 2008.

CAVADINO, Mick y DIGNAM, James, The Penal system: Introduction, cuarta edición, Londres: Sage Publications, 2007.

CHAPMAN, Tim, "Revising the national outcomes and standards for criminal justice social work services in Scotland", en MCNEILL, Fergus, RAYNOR, Peter y TROTTER, Chris, Offender Supervision: New Directions in Theory, Research and Practice, Cullompton: Willian, 2010, pp. 430-450.

CHRISTIE, Nils, "Conflicts as property", British Journal of Criminology, vol. 17, $\mathrm{n}^{\circ} 1$ (1977), pp. 1-15.

CLEAR, Todd, y KARP, David, The Community Justice Ideal: Preventing crime and achieving justice, Oxford: Westview Press, 1999.

COHEN, Stan, Vision of social control, Cambridge: Polity Press, 1985. 
ROBINSON, Gwen; McNEILL, Fergus; MARUNA, Shadd. "Castigo en sociedad: La Improbable persistencia de la probation y otras sanciones y medidas comunitarias".

CORBETT, Ronald P., "Reinventing probation and reducing youth violence: Boston's Operation Night Light" en: KARP, David R. y TODD, Clear (Eds.), What is community justice? Case studies of restorative justice and community supervision, Thousand Oaks, CA: Sage Publications, 2002, pp. 111-134.

COUNCIL OF EUROPE "Committee of Ministers: Recommendation $n^{\circ} R$ (92) 16 of the Committee of Ministers to member states on the European rules on community sanctions and measures: Adopted by the Committee of Ministers on 19 October 1992 at the 482nd meeting of the Ministers' Deputies", p. 11, en: https://wcd.coe.int/com.instranet.InstraServlet?command=com.instranet.CmdBlobGet $\underline{\text { \&InstranetImage }=574882 \& \text { SecMode }=1 \& \text { DocId }=605174 \& \text { Usage }=2 \quad[\text { Visitado }}$ 21.08.2013].

CRAWFORD, Adam; HUCKLESBY, Anthea, Legitimacy and Compliance in Criminal Justice, Londres: Routledge, 2012.

CULLEN, Francis, "The twelve people who saved rehabilitation: how the science of criminology made a difference", Criminology, vol. 43, nº 1 (2005), pp. 1-42.

DELEUZE, Gilles, "Postscript on the Societies of Control", en: DELEUZE, Gilles, Negotiations: 1972-1990, New York: Columbia University Press, (1995).

DICKEY, Walter J. y SMITH, Michael E., "Dangerous Opportunity: Five futures for community corrections: The report from the focus group", Washington D.C.: U.S. Department of Justice, Office of Justice Programs, 1998, p. 6. Puede accederse vía electrónica en http://www.ojp.usdoj.gov/probation/ [Visitado 21.08.2013].

DIGNAN, James, Understanding victims and restorative justice, Maidenhead: Open University Press, 2005.

DILLER, Rebekah; GREENE, Judith; JACOBS, Michelle, Maryland's Parole Supervision Fee: A Barrier to Reentry, New York: Brennan Center for Justice, 2009.

DUFF, Anthony, Punishment, Communications, and Community, Oxford: Oxford University Press, 2001.

DURKHEIM, Emile, “Two laws of penal evolution”, Economy and Society, vol. 2 (1973), pp. 278-308.

DURNESCU, Ioan, "An exploration of the purposes and outcomes of probation in European jurisdictions", Probation Journal, vol. 55, n 3 (2008), pp. 273-281.

, "Pains of Probation: Effective Practice and Human Rights", International Journal of Offender Therapy and Comparative Criminology, vol. 55, $\mathrm{n}^{\circ} 4$ (2011), pp. 530-545.

EHLERS, Louise, "Probation in Africa" en: CANTON, Rob y HANCOCK, David (Eds.), Dictionary of Probation and Offender Management, Cullompton: Willian, 2007, pp. 228-229.

ERIKSSON, Anna, Justice in Transition: Community Restorative Justice in Northern Ireland, Cullompton, Willian, 2009.

ETZIONI, Amitai, A Responsive Society: Collected Essays on Guiding Deliberate Social Change, San Francisco, California: Jossey-Basee, 1991.

FARABEE, David, Rethinking rehabilitation: Why can't we reform our criminals?, Washington: American Enterprise Institute Press, 2005.

FARRAL, Stephen y SPARKS, Richard, "Introduction", Criminology and criminal justice, vol. 6, no 1 (2006), pp. 7-17. 
Polít. crim. Vol. 9, № 17 (Julio 2014), Art. 5, pp. 147-181.

[http://www.politicacriminal.cl/Vol_09/n_17/Vol9N17A5.pdf]

FEELEY, Malcolm y SIMON, Jonathan, "The New Penology: Notes on the emerging strategy of corrections and its implications", Criminology vol. 30 (1992), pp. 449474.

, "Actuarial justice: The emerging new criminal law", en: NELKEN, D. (Ed.), The futures of criminology, Londres: Sage Publications, 1994, pp. 173-201

FITZGIBBON, Wendy, Probation and Social Work on Trial, London: Palgrave Macmillan, 2011.

FOUCAULT, Michel, Discipline and punish: The Birth of Prison, Londres: Allan Lane, $1975 / 1977$.

GARLAND, David, Punishment and Welfare, Aldershot: Gower, 1985.

, Punishment and Modern Society, Oxford: Clarendon, 1990.

"The Limits of the Sovereign State: Strategies of Crime Control in Contemporary Society", British Journal of Criminology, vol. 36, no 4 (1996), pp. 445-471.

, "Probation and the reconfiguration of crime control", en: BURNETT, Ros (Ed.), The Probation Service: Responding to Change (Proceedings of the Probation Studies Unit First Colloquium), Oxford: University of Oxford Centre for Criminological Research, 1997, pp. 2-10.

, The Culture of control, Oxford: Oxford University Press, 2001.

GLAZE, Lauren E. y BONCZAR, Thomas P., "Bureau of Justice Statistics, Probation and Parole in the United States. NCJ228230", Washington D.C.: Departamento de Justicia de Estados Unidos (2009). Puede accederse vía electrónica en http://www.bjs.gov/index.cfm?ty=pbdetail\&iid=1764 [Visitado 21.08.2013].

GRATTET, Ryken, PETERSILIA, Joan, LIN, Jeffrey y BECKMAN, Marlene, "Parole Violations and Revocations in California: Analysis and Suggestions for Action", Federal Probation, vol. 73, no 1 (2009), pp. 2-11.

HARDING, John., "A Community Justice Dimension to Effective Probation Practice", The Howard Journal of Criminal Justice, vol. 39 (2000), pp. 132-149.

, "Which Way Probation? A Correctional or Community Justice Service?", Probation Journal, vol. 50, no 4 (2003), pp 369-373.

HOME OFFICE, Rebalancing the criminal justice system in favour of the law-abiding majority: Cutting Crime, Reducing Re-offending and Protecting the Public, Londres: Home Office, 2006.

HULSMAN, Louk, Strategies to reduce violence in society: civilising the criminal justice system, an address to the annual meeting of the Howard League for Penal Reform (Inédito), 1976.

HUTCHINSON, Steven, "Countering catastrophic criminology Reform, punishment and the modern liberal compromise", Punishment \& Society, vol. 8, n 4 (2006), pp. 443467.

KARP, David; CLEAR, Todd, What is community justice? Case Studies of restorative and community Justice, Boston: Pine Forge, 2002.

KEMSHALL, Hazel y MAGUIRE, Mike, "Public protection, partnership and risk penality: the multi-agency risk management of sexual and violent offenders", Punishment and society, vol. $3, \mathrm{n}^{\circ} 2$ (2001), pp. 237-264. 
ROBINSON, Gwen; McNEILL, Fergus; MARUNA, Shadd. "Castigo en sociedad: La Improbable persistencia de la probation y otras sanciones y medidas comunitarias".

KENDALL, Kathleen, "Dangerous Thinking: A Critical History of Correctional Cognitive Behaviouralism" en: MAIR, George (Ed.), What Matters in Probation?, Cullompton: Willan Publishing, pp. 53-89.

LIEBLING, Alison y CREWE, Ben, "Prisons beyond the new penology: The shifting moral foundation of prison management", en: SIMON, Jonathan y SPARKS, Richard (Eds.), The Sage Handbook of Punishment and Society, Londres: SAGE, 2013, pp. 283-307.

LYNCH, Mona, "Waste Managers? The New Penology, Crime Fighting, and Parole Agent Identity”, Law \& Society Review, Vol. 32, n 4 (1998), pp. 839-870.

LYOTARD, Jean-Francois, The Postmodern condition: A report on Knowledge, Manchester: University Press, 1984.

MAIR, George; CROSS, Noel; TAYLOR, Stuart, The use and impact of the Community Order and the Suspended Sentence Order, Londres: Centre for Crime and Justice Studies, 2007.

MALONEY, Dennis, BAZEMORE, Gordon y HUDSON, Joe, "The end of probation and the beginning of community justice", Perspectives, vol. 25, no 3 (2001), pp. 24-30.

MARUNA, Shadd e IMMARIGEON, Russ, After Crime and punishment: Pathway to offender reintegration, Cullompton: Willan, 2004.

MARUNA, Shadd y KING, Anna, "Selling the Public on Probation: Beyond the Bib", Probation Journal, vol. 55, no 4 (2008), pp. 337-351.

MARUNA, Shadd y LEBEL, Thomas P., "Welcome Home? Examining the "Reentry Court" Concept from a Strengths-based Perspective", Western Criminology Review, Vol. 4, no 2 (2003), pp. 91-107.

MAY, David, C.; WOOD, Peter B., Ranking Correctional Punishments: Views from Offenders, Practitioners, and the Public, Durham, North Carolina: Carolina Academic Press, 2010.

McCULLOCH, Trish y McNEILL, Fergus, "Consumer Society, commodification and offender management", Criminology and Criminal Justice, vol. 7, no 3 (2007).

McEVOY, Kieran y MIKA, Harry, "Punishment, Policing and Praxis: Restorative Justice and Non-Violent Alternatives to ParaMilitary Punishments in Northern Ireland", Policing and Society, vol. 11 (2001), pp. 359-382.

McEVOY, Kieran y MALLINDER, Louise, "Amnesties, transitional justice and governing through mercy", en: SIMON, Jonathan; SPARKS, Richard (Eds.), The Sage Handbook of Punishment and Society, Londres: SAGE, 2013, pp. 434-462.

McGUIRE, James, What Works: Reducing Reoffending, Chichester: Wiley, 1995.

McIVOR, Gill, "Paying back: 30 years of unpaid work by offenders in Scotland", European Journal of Probation, vol. 2, nº 1 (2010), pp. 41-61.

McIVOR, Gill, BEYENS, Kristel, BLAY, Ester y BOONE, Miranda, "Community service in Belgium, the Netherlands, Scotland and Spain: a comparative perspective", European Journal of Probation, vol. 2, no 1 (2010), pp. 82-98.

McNEILL, Fergus, "Probation, credibility and justice", Probation Journal, vol. 58, $\mathrm{n}^{\circ} 1$ (2011), pp. 9-22.

MINISTRY OF JUSTICE, Breaking the Cycle: Effective punishment, rehabilitation and sentencing of offenders, Londres: Ministry of Justice, 2010. 
Polít. crim. Vol. 9, № 17 (Julio 2014), Art. 5, pp. 147-181.

[http://www.politicacriminal.cl/Vol_09/n_17/Vol9N17A5.pdf]

MORRIS, Norval y TONRY, Michael, Between prison and probation: Intermediate Punishments in a Rational sentencing System, Oxford: Oxford University Press, 1990.

MUNDEN, David, TEWKSBURY, Richard, y GROSSI, Elizabeth, "Intermediate Sanctions and the Halfway Back Program in Kentucky", Criminal Justice Policy Review September, vol. 9, no 3 (1999), pp. 431-449.

NATIONAL AUDIT OFFICE, National Probation Service: The supervision of Community Orders in England and Wales. Londres: TSO, 2008.

NATIONAL PROBATION SERVICE, National Probation Service: The supervision of Community Orders in England and Wales. Londres: TSO, 2005.

NELLIS, Mike, "Creating community justice" en: BALLINTYNE, Scott, PEASE, Kenneth y McLAREN, Vic (Eds.), Secure Foundations: Key Issues in Crime Prevention, Crime Reduction and Community Safety, Londres: Institute for Public Policy Research, 2000, pp. 67-86.

, "Dim prospects: Humanistic Values and the fate of community Justice", en: WINSTONE, Jane y PAKES, Francis (Eds.), Community Justice: Issues for probation and criminal justice, Cullompton: Willian, 2005, pp. 33-51.

"Electronic monitoring: Towards integration into offender Management", en MCNEILL, Fergus; RAYNOR, Peter; TROTTER, Chris (Eds.), Offender Supervision: New directions in theory, research and practice, Cullompton: Willan, 2010, pp. 509-533.

O’MALLEY, Pat, "Monetized Justice: Money and Punishment in Consumer Societies", en: SIMON, Jonathan y SPARKS, Richard, (Eds.), The Sage Handbook of Punishment and Society, Londres: Sage (2013), pp. 375-390

PADFIELD, Nicola y MARUNA, Shadd, "The revolving door at the prison gate: Exploring the dramatic increase in recalls to prison", Criminology and criminal justice, vol. 6, no 3 (2006), pp. 329-352.

PADFIELD, Nicola, VAN ZYL SMIT, Dirk y DÜNKEL, Frieder, Release from prison: European policy and practice, Cullompton: Willian, 2010.

PAGE, Joshua, "Punishment and inequality" en: SIMON, Jonathan y SPARKS, Richard (Eds.), The Sage Handbook of Punishment and Society, Londres: SAGE, 2013, pp. 169-185.

PAYNE, Brian K., y GAINEY, Randy R., "A Qualitative Assessment of the Pains Experienced on Electronic Monitoring”, International Journal of Offender Therapy and Comparative Criminology, vol. 42, nº 2 (1998), pp. 149-163.

PEASE, Ken, "Community Service Orders", en: TONRY Michael y MORRIS, Norval (Eds.), Crime and Justice, Chicago: Chicago University Press, 1985, pp. 51-94.

PETERS, Antoine G., "Main currents in criminal law theory", en: DIJK, Jan van, HAFFMANS, C. et. al (Eds.), Criminal Law in Action. Londres: Kluwer law and taxation publishers, 1986, pp. 19-36.

PETERSILIA, Joan R., "When probation becomes more dreaded than prison", Federal Probation, vol. 54 (1990), pp. 23-27.

PETERSILIA, Joan R., y DESCHENES, Elizabeth, "Perceptions of punishment: Inmates and staff rank the severity of prison versus intermediate sanctions", The prison Journal, vol. 74, no 3 (1994), pp. 306-328. 
ROBINSON, Gwen; McNEILL, Fergus; MARUNA, Shadd. "Castigo en sociedad: La Improbable persistencia de la probation y otras sanciones y medidas comunitarias".

PRATT, John, BROWN, David y BROWN, Mark, The New Punitiveness: Trends, Theories, Perspectives, Cullompton: Willian, 2005.

RAYNOR, Peter, Probation is an alternative to custody, Aldershot: Avebury, 1988. , "Community penalties: Probation, "What Works" and offender management", en: MAGUIRE, Mike, MORGAN, Rod y REINER, Robert (Eds.), The Oxford Handbook of Criminology, $4^{\mathrm{a}}$ edición, Oxford: Oxford University Press, 2007, pp. $1061-1099$.

RAYNOR, Peter; ROBINSON, Gwen, Rehabilitation, Crime and Justice, Basingstoke: Palgrave Macmillan, 2009.

RAYNOR, Peter y VANSTONE, Maurice, "Towards a correctional service" en: GELSTHORPE, Loraine; MORGAN, Rod (Eds.), Handbook of Probation, Cullompton: Willan, 2007, pp. 59-89.

ROBERTS, Julian V. y HOUGHT, Mike, "Custody or community? Exploring the boundaries of public punitiveness in England and Wales", Criminology and Criminal Justice, vol. $11 \mathrm{n}^{\circ} 2$ (2011), pp. 181-197.

ROBINSON, Gwen, "What works in offender Management?", Howard Journal of criminal justice, vol. 44, no 3 (2005), pp. 307-318.

"Late-modern rehabilitation: the evolution of a penal strategy", Punishment and Society, vol. 10, n⿳ 4 (2008), pp. 429-445.

ROBINSON, Gwen y McNEILL, Fergus, "Purposes matter: examining the "ends" of probation practice", en: MAIR, George (Ed.), What matters in probation, Cullompton: Willian, 2004, pp. 277-304.

, "Exploring the dynamics of compliance with community penalties", Theoretical Criminology, vol. 12, no 4 (2008), pp. 431-449.

ROCHE, Declan, "Restorative Justice and the Regulatory State in South African Townships", The British Journal of Criminology, vol. 42, no 3 (2002), pp. 514-533.

ROSE, Nikolas, "Government and control", British Journal of Criminology, vol. 40, $\mathrm{n}^{\circ} 2$ (2000), pp. 321-339.

ROSS, Robert R., FABIANO, Elizabeth A. y EWLES, Crystal D., "Reasoning and Rehabilitation", International Journal of Offender Therapy and Comparative Criminology, vol. 32, no. 1 (1988), pp 29-35.

SABLE, W.J.; COUTURE H., Prison Inmates at Midyear 2007, Washington, DC: Bureau of Justice Statistics, 2008.

SCOTTISH PRISONS COMMISSION, Scotland's Choice, Edimburgo: Scottish Prison Commission, 2008.

SIGLER, Robert T. y McGRAW, Bridgett, “Adult Probation and Parole Officers: Influence of Their Weapons, Role Perceptions and Rule Conflict", Criminal Justice Review, vol. 9 (1984), pp. 28-32.

SIMON, Jonathan, "The emergence of a risk society: Insurance, law and the State", Socialist Review, vol. 95 (1987), pp. 61-89.

, "The Ideological effects of actuarial practices", Law \& Society Review, vol. 22 (1988), pp. 771-800.

, Jonathan, Poor Discipline: Parole and the social control of the underclass 18901990, Londres: University of Chicago Press, 1993.

SOCIAL EXCLUSION UNIT, Reducing re-offending by ex prisoners, Londres: Home Office, 2001. 
Polít. crim. Vol. 9, № 17 (Julio 2014), Art. 5, pp. 147-181.

[http://www.politicacriminal.cl/Vol_09/n_17/Vol9N17A5.pdf]

SUCHMAN, Mark C., "Managing Legitimacy: Strategic and Institutional Approaches", The Academy of Management Review, Vol. 20, $\mathrm{n}^{\circ} 3$ (1995), pp. 571-610.

SKYES, Gresham M., The Society of Captives: A Study of a Maximum Security Prison, Princeton, New Jersey: Princeton University Press, 1958.

TONRY, Michael y LYNCH, Mary, "Intermediate Sanctions", Crime and Justice, vol. 20 (1996), pp. 99-144.

TRAVIS, Jeremy, But they all come back: facing the challenges of prisoner reentry, Washington, DC: The Urban Institute Press, 2005.

TUCKER, Susan y CADORA, Eric, "Justice Reinvestment: to invest in public safety by reallocating justice dollars to refinance education, housing, healthcare, and jobs", Ideas for an Open Society, vol. 3, no 3 (2003), Nueva York: Open Society Institute: http://www.opensocietyfoundations.org/sites/default/files/ideas_reinvestment.pdf [Visitado 04.08.2013].

VANSTONE, Maurice, Supervision offenders in the community, Aldershot: Ashgate, 2004.

VASS, Anthony, Alternative to prison, Londres: Sage Publications, 1990.

VON KALMTHOUTH, Anton M. y DURNESCU, Ioan (Eds.), "Probation in Europe”, Nijmegen: Wolf Legal Publishers/CEP, 2008.

WACQUANT, Loïc, "Prisoner reentry as myth and ceremony", Dialectical Anthropology, vol. 34, n 4 (2010). pp. 605-620.

WARD, Tony y MARUNA, Shadd, Rehabilitation, Londres: Routledge, 2007.

WEBER, Max, "Class, Status, Party" en: GERTH, H.H.; WRIGHT MILLS, C. (Eds.), From Max Weber: Essays in Sociology, Nueva York: Oxford University Press, 1946, pp. 180-195.

WINSTONE, Jane y PAKES, Francis (Eds.), Community Justice: Issues for probation and criminal justice, Cullompton: Willian, 2005.

WODAHL, Eric, OGLE, Robbin y HECK Cary, "Revocation trends: a threat to the legitimacy of community based corrections", The Prison Journal, vol. 91, n 2 (2011), pp. 207-226.

ZEDNER, Lucia, "Reparation and Retribution: Are They Reconcilable?", The Modern Law Review, Vol. 57, n² 2 (1994), pp. 228-250. 